\title{
Chapter 9 - EXPERIMENTAL INVESTIGATION OF ROUGHNESS EFFECTS ON TRANSITION ON BLUNT SPHERICAL CAPSULE SHAPES
}

\author{
Rolf Radespiel and Syed R.C. Ali \\ Technische Universität Braunschweig, Institute of Fluid Mechanics \\ GERMANY \\ Rodney Bowersox and Andrew Leidy \\ Texas A\&M University, College Station \\ USA \\ Hideyuki Tanno \\ JAXA Kakuda Space Center \\ JAPAN \\ Lindsay C. Kirk \\ NASA Johnson Space Center \\ USA \\ Eli Reshotko \\ Case Western Reserve University \\ USA
}

\section{NOMENCLATURE}

$b \quad$ wall thickness

$c \quad$ specific heat

$D, d \quad$ diameter of the wind tunnel model

E voltage

$f \quad$ frequency

$H \quad$ enthalpy

$h \quad$ convective heat transfer coefficient

$k$ peak-to-valley roughness height

$M \quad$ Mach number

$P S D$ power spectral density

$Q \quad$ heat flux rate

$R \quad$ radius of the model

$R_{a} \quad$ mean surface roughness

Re Reynolds number

$R_{d} \quad$ Reynolds number based on model diameter

$R e_{k k} \quad$ Reynolds number based on roughness height and flow conditions at this height

$R e / l \quad$ Unit Reynolds number of freestream flow 


\title{
EXPERIMENTAL INVESTIGATION OF ROUGHNESS EFFECTS ON TRANSI- TION ON BLUNT SPHERICAL CAPSULE SHAPES
}

\author{
$R e_{\theta} \quad$ Reynolds number based on boundary layer momentum thickness \\ St Stanton number \\ $T$ temperature \\ $t \quad$ time \\ $u \quad$ streamwise velocity \\ $x, y, z \quad$ Cartesian coordinates \\ $\theta \quad$ momentum thickness of boundary layer \\ $\kappa \quad$ thermal conductivity \\ $\nu \quad$ kinematic viscosity \\ $\rho \quad$ density \\ Subscripts \\ conv convective \\ $e \quad$ at boundary layer edge \\ mean mean value \\ $p \quad$ at constant pressure \\ $R M S$ root mean square \\ tr transitional \\ $\infty \quad$ freestream \\ $w \quad$ wall \\ $0 \quad$ at stagnation point
}

\subsection{INTRODUCTION}

Heat transfer on hypersonic vehicles with blunt nose geometries during re-entry or at sustained hypersonic flight is important for designing the thermal protection system. Turbulent heat transfer is generally much larger than laminar heating. Therefore, the onset of turbulent flow due to boundary-layer transition must be predicted during design phases of the vehicle. This is a difficult task since important flow parameters such as Reynolds number, stagnation enthalpy and wall temperatures vary largely along the flight trajectory. Hence, sensitivity of the flow with respect to vehicle details that augment transition processes present for an ideally smooth vehicle varies largely, too. One of these parameters is surface roughness. Roughness can be an inherent feature of the surface material used for thermal protection, but it often changes during flight, due to chemical interactions of the surface materials with the high-temperature near-wall flow, resulting in a range of complex roughness manifestations.

Computational prediction methods for boundary-layer transition of hypersonic flow over blunt shapes which take these effects into account based on first principles are not yet available. Present computational design tools use theoretical considerations and assumptions to simplify the computation task. Also, the computations usually involve uncertainties due to the numerical approximation of the continuous problem. Therefore, detailed experiments in a suited flow environment are needed for validating prediction methods and for verifying new vehicle designs. While experiments by well-documented flight tests could be considered as an ultimate proof of validation, this approach is generally not feasible, due to extremely high cost and specific uncertainties related to flight-testing as well. Therefore, wind tunnel testing in hypersonic facilities must be used. Unfortunately, hypersonic wind tunnels large enough to allow transition experiments of blunt shapes at reasonably high Reynolds 


\section{EXPERIMENTAL INVESTIGATION OF ROUGHNESS EFFECTS ON TRANSITION ON BLUNT SPHERICAL CAPSULE SHAPES}

numbers usually have significant flow distortions in their test section flow. These distortions are primarily comprised of acoustic noise originating from the high-velocity nozzle boundary layer. However, they also contain fluctuations of flow total temperature due to temperature variations in the tunnel flow reservoir before the nozzle, and vorticity disturbances due to turbulence generated in the tunnel settling chamber.

Generic blunt noses shapes are often spherical. The boundary layer of hypersonic flows over spherical nose shapes does generally not exhibit modal instabilities such as Tollmien-Schlichting modes, up to very high Reynolds numbers. This holds true for blunt bodies with spherical noses also at significant angles of attack. However, experiments indicate that transition on such blunt shapes appears under many circumstances. Note that blunt windward shapes combined of sphere segments and cone portions behave differently, as they exhibit modal instabilities.

Heat flux augmentation around the stagnation point and transition onset in wind tunnels were investigated by a number of researchers for nominally smooth capsule shapes at hypersonic speeds [1], [2]. Using models of different size and correlations between heat transfer sensors, Marineau et al [2] emphasize the importance of vortical disturbance size originating from the freestream relative to model size and the vortex augmentation by vortex stretching. Ali et al [3] measure similar phenomena, however they also observe significant sensitivity to small, subcritical surface roughness at roughness heights typical for instrumented wind tunnel models. For isolated roughness elements on blunt shapes, there exist a large number of experiments, see Ref. [4] as an example. While these protuberances often trip the boundary layer state from laminar to turbulent, they can also generate modal instabilities, which grow in the mean-flow wake of these disturbances. Ref. [5] presents the analysis of such wake instabilities in the accelerated boundary layer of an Apollo-shape capsule at angle of attack, indicating a rather short stream-wise extent of eigenmode growth, compared to flat-plate results, and presents corresponding measured surface fluctuations. The influence of flow enthalpy on transition with and without roughness elements is of particular interest. Here, first results from the HIEST facility became available over recent years [6], with corresponding computations indicating relative boundary layer parameters [7]. The latter indicate good correlation with unit Reynolds number.

Most representative for the effect surface roughness during hypersonic flight is distributed roughness. Distributed roughness generates streamwise vortices, which are rather independent of freestream disturbances. These vortices possibly grow in the area close to the stagnation point. A candidate mechanism for this is transient growth. Transient growth describes the superposition of slightly damped, non-orthogonal modes of the boundary layer. For suited boundary layer parameters, the resulting disturbing magnitudes may become large. Reshotko and Tumin [8], [9] considered the theory of optimal disturbances for compressible stagnation point flow. They find that optimal boundary layer disturbances are stationary streamwise vortices of zero frequency and with particular spanwise wave numbers. Hence, transient growth can be significant in transition to turbulence for blunt shapes with otherwise stable modes. It bypasses eigenmode growth and therefore, leads directly to parametric instabilities and mode interactions of large boundary layer disturbances, followed by breakdown. This is called roughness induced transition. Ref. [9] analyzed growth calculations of axisymmetric stagnation point flow for the effects of roughness height, wall-to-edge temperature ratio and surface curvature. The resulting model is

$$
R e_{\theta, t r}=180\left(\frac{k}{\theta}\right)^{-1}\left(\frac{T_{e}}{2 T_{w}}\right)^{-1.27}
$$

for which the scaling coefficient was based on carefully analyzed wind tunnel data [10], [11]. The validity of this model obviously breaks for large roughness heights, as the flow disturbances created by large roughness would directly bypass any linear growth mechanism. More recently, new experiments became available which can be used to substantiate the theoretical findings. Hollis performed wind tunnel experiments with a range of distributed sand grain and patterned roughness setups for various blunt nose shapes [12] and he derived further empirical correlations [13]. Leidy et al set up dedicated transition experiments in support of the transient-growth 


\section{EXPERIMENTAL INVESTIGATION OF ROUGHNESS EFFECTS ON TRANSI- TION ON BLUNT SPHERICAL CAPSULE SHAPES}

based correlation [14]. Further substantiation can be expected from numerical computations that go beyond the limitations associated with transient growth theory, for example solutions of the parabolized stability equations, PSE, and direct numerical simulations, DNS. The Research Group AVT 240 of the Science Technology Organization has performed significant research works in numerical analysis of Apollo-type capsule shapes, as presented in a companion paper [15]. This confirmed the theory-based relationship of Eqn. (1) remarkably well. Boundary layer transition on blunt, spherical nose shapes often depends on freestream disturbances of the facility, as noted above. Hence, new approaches and results in analyzing freestream disturbances in hypersonic wind tunnel facilities are presented in another companion paper [16].

The present contribution reviews experimental investigations of roughness effects on boundary layer transition on capsule geometries with spherical windward geometries, also performed as part of the Research Group AVT 240. We describe experiments in three wind tunnel facilities. The ACE Tunnel of Texas AM University, USA, provided Mach 6 experiments with distributed roughness at relatively low Reynolds numbers, $2.5 \cdot 10^{5}$ $<R e_{d}<5 \cdot 10^{5}$, with d denoting the capsule diameter. Observed boundary layer transition are compared to correlations based on transient growth theory. Larger Reynolds numbers, $1 \cdot 10^{6}<R e_{d}<3 \cdot 10^{6}$, could be assessed in the hypersonic Ludwieg tube of TU Braunschweig, Germany. These experiments varied fluctuation levels of the freestream. Transition is already observed at rather low, subcritical roughness values in the order of $20 \mu \mathrm{m}$ (peak to valley) on a $170 \mathrm{~mm}$ capsule model. Roughness induced transition is obtained for larger roughness of around 100-250 $\mu \mathrm{m}$. Additionally, disturbance levels within the shock layer, close to the edge of the boundary layer, were measured by hot-wire anemometry. Effects of total flow enthalpy on transition with isolated roughness were investigated in the HIEST facility of JAXA, Japan. Here, a model insert with roughness elements for tripping transition to turbulence was employed and flow total enthalpy along with Reynolds number was varied.

\subsection{TRANSITION EXPERIMENTS IN ACE WIND TUNNEL}

\subsubsection{Experimental Setup}

Tests were conducted at Mach 6 on a thin-walled, scaled model of the Orion CEV mounted in the Actively Controlled Expansion (ACE) wind tunnel at a 28 degree angle of attack. ACE is an open-circuit hypersonic blowdown pressure-vacuum tunnel that can achieve Mach 5-8. The Mach number on the method of characteristics designed nozzle is adjusted by changing the throat height. ACE has a maximum run time of 40 seconds and a unit Reynolds number range is $0.3-10 \cdot 10^{6} / \mathrm{m}$.

The stainless steel model is comprised of a conical base and a $7.62 \mathrm{~cm}$ diameter spherical cap with a wall thickness of $0.76 \mathrm{~mm}$. The cap was coated in samples of aluminum oxide sandgrit to give the face five different quasi-uniform distributed roughness heights. It was also spray-painted with six coats of high-temperature black spray paint to minimize the infrared reflectivity of the surface. The roughness height for each sample was characterized using a laser profilometer. The laser scans were processed according to the $30 \%$ exceedance criteria described by Batt and Legner [11]. The thermal properties of the face were approximated using the method of layers which assumes that thermal capacities and resistances of different materials are additive and the surface emissivity is unity. The roughness heights and associated thermal properties for each sandgrit sample are given in Table 9-1.

Surface temperature measurements on the capsule face were sampled continuously throughout the run at 60 Hz using a FLIR SC3000 IR camera. The gallium arsenide detector is sensitive to longwave infrared radiation within the range of $8-9$ micrometers and has $320 \times 240$ pixel resolution. The camera was positioned facing 30 degrees downstream from normal to the tunnel sidewall at a distance of $32.8 \mathrm{~cm}$ from the center of the capsule face. The configuration is given in Figure 9-1. Data were collected in ThermaCAM Researcher and opened in 
ExaminIR, where tif files containing temperature values at each pixel were generated for every frame.
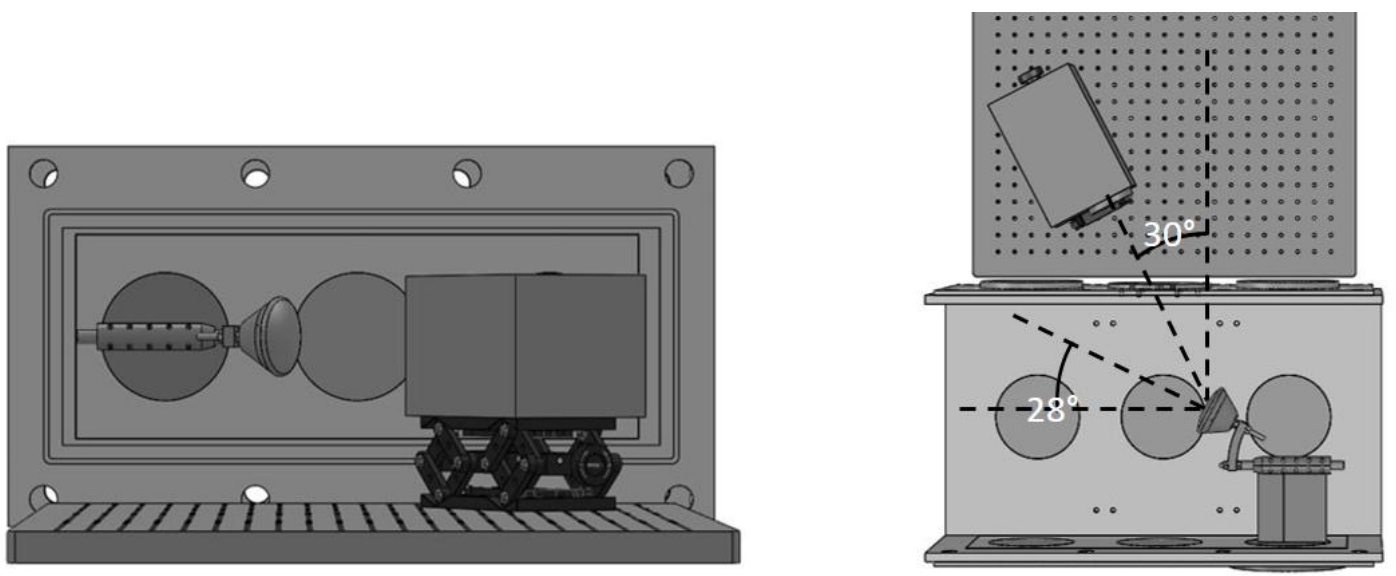

Figure 9-1: Experimental setup side (left) and top (right) views

Table 9-1: Capsule thermal properties based on roughness height

\begin{tabular}{cccc}
\hline \hline Grit & Roughness Height & $\rho c d\left(\frac{J}{m^{2} / K}\right)$ & $\kappa d\left(\frac{W}{K}\right)$ \\
\hline G36 & 665 & 3870 & $1.07 \mathrm{E}-3$ \\
G46 & 487 & 3750 & $1.08 \mathrm{E}-3$ \\
G60 & 370 & 3560 & $1.12 \mathrm{E}-3$ \\
G80 & 271 & 3530 & $1.13 \mathrm{E}-3$ \\
G120 & 150 & 3460 & $1.18 \mathrm{E}-3$ \\
smooth & 3.6 & 3150 & $4.67 \mathrm{E}-3$ \\
\hline
\end{tabular}

\subsubsection{Method}

Tunnel runs were conducted at four unit Reynolds numbers: $3.4 \cdot 10^{6} / \mathrm{m}, 4.5 \cdot 10^{6} / \mathrm{m}, 5.5 \cdot 10^{6} / \mathrm{m}$, and $6.6 \cdot 10^{6} / \mathrm{m}$, with the six surface roughness heights listed in Table 9-1, making for a test matrix of 24 different conditions. Average tunnel conditions for all of the runs are listed in Table 9-2. The mean temperature varied by less than $\pm 5 \mathrm{~K}$ and the Reynolds number by less than $\pm 3 \%$ over the 15 second time range considered for each run.

The temperature maps generated by the IR camera were transformed using a ray tracing code to view the capsule head-on. Centerline profiles were established using the new coordinate system, with y being the coordinate along the centerline, and $y / R$ defined as -1 at the centerline point on the most upstream side of the face, and $y / R$ defined as 1 on the most downstream centerline point on the face.

From the temporally uninterrupted surface temperature data, the convective heat flux is given by Eq. (2).

$$
\dot{Q}=\rho c b \frac{\partial T}{\partial t}-\kappa b \nabla^{2} T
$$

where $\rho$ is material density, $c$ is specific heat, $b$ is the effective capsule wall thickness, $T$ is surface temperature, $t$ is time, $\kappa$ is thermal conductivity. The temporal temperature derivative term was approximated for each pixel 


\section{EXPERIMENTAL INVESTIGATION OF ROUGHNESS EFFECTS ON TRANSI- TION ON BLUNT SPHERICAL CAPSULE SHAPES}

through a linear fit for frames between 12-27 seconds. These values were multiplied by the constants specific to roughness, listed in the second column of Table 9-2, to get the first term of the convective heat flux. Since the capsule has a thin wall that is backed by air, the assumptions were that wall normal temperature gradient through the material is zero and no heat is lost to the inside of the shell. The lateral conductive term in Eq. (2), was found to account for less than $5 \%$ of the convective heat flux, so it was removed from consideration for simplicity.

The convective heat flux allowed for the calculation of the Stanton number by Eq. (3).

$$
S t=\frac{\dot{Q}_{c o n v}}{\rho_{\infty} u_{\infty} c_{p}\left(T_{0}-T_{w}\right)}
$$

where $\rho_{\infty}$ is the freestream density, $u_{\infty}$ is the freestream velocity, $c_{p}$ is the specific heat measured at constant pressure, and $T_{0}$ and $T_{w}$ are the total freestream and wall temperatures, respectively.

Normalization of the Stanton number by a value from the upstream side of the face allowed for the identification of the approximate transition location on the runs where transition was present. This normalizing quantity was typically the maximum centerline Stanton number value on the upstream side.

\subsubsection{Results}

The normalized Stanton number centerline plots presented in Figure 9-2 align the similarly shaped curves and highlight the points in which some curves diverge from the group. In this figure, it is clear that there is much overlap in the data points of different roughness sizes at the lowest Reynolds numbers, $R e_{d} \approx 2.6 \cdot 10^{5}$ and $R e_{d} \approx 3.4 \cdot 10^{5}$. However, at the highest Reynolds numbers, $R e_{d} \approx 4.1 \cdot 10^{5}$ and $R e_{d} \approx 4.9 \cdot 10^{5}$, larger roughness data points diverge from the smaller roughness points at some downstream value on the capsule face. The beginning of this data point divergence signifies a difference in the rate of heat transfer, which is believed to be the onset of transition from laminar to turbulent flow. Commonality in the centerline profile divergence location as well as elevated heating on the downstream side of the capsule face for the largest two roughness sizes (G36 and G46) at $R e_{d} \approx 4.9 \cdot 10^{5}$ and the largest roughness size at $R e_{d} \approx 4.1 \cdot 10^{5}$ suggests that the boundary layer transitioned on the upstream side of the capsule face. The onset of transition for these test cases is estimated to occur at a centerline position of $\mathrm{y} / \mathrm{R}$ between -0.45 and -0.30 . Other profiles show potential for transition farther downstream. These three cases include the largest roughness size at $R e_{d} \approx 3.4 \cdot 10^{5}$ as well as G60 and G46 at $R e_{d} \approx 4.9 \cdot 10^{5}$ and $R e_{d} \approx 4.1 \cdot 10^{5}$, respectively. Table 9-2 summarizes the conditions for all runs that showed elevated downstream heating.

Table 9-2: Flow Conditions for Runs with Elevated Downstream Heating

\begin{tabular}{ccccccccccc}
\hline \hline Run & $\mathrm{Grit}$ & $\mathrm{Re}_{d}$ & $\mathrm{k} / \Theta$ & $\mathrm{k} / \delta$ & $\mathrm{y} / \mathrm{R}$ & $\mathrm{T}_{w}(K)$ & $\mathrm{T}_{e}(K)^{a}$ & $\mathrm{U}_{e}(m / s)^{a}$ & $\rho_{e}\left(k g / m^{3}\right)^{a}$ & $\operatorname{Re}_{\theta}$ \\
\hline 2790 & 36 & $4.9 \mathrm{E} 5$ & 17.0 & 1.51 & -0.42 & 394 & 413 & 126 & 0.121 & 25.4 \\
2788 & 36 & $4.1 \mathrm{E} 5$ & 16.6 & 1.46 & -0.36 & 393 & 413 & 141 & 0.0995 & 23.6 \\
2789 & 36 & $3.3 \mathrm{E} 5$ & 14.0 & 1.15 & 0.17 & 386 & 400 & 244 & 0.0669 & 34.3 \\
2786 & 46 & $5.0 \mathrm{E} 5$ & 12.3 & 1.08 & -0.38 & 394 & 413 & 135 & 0.120 & 27.5 \\
2783 & 46 & $4.1 \mathrm{E} 5$ & 11.6 & 0.99 & -0.22 & 392 & 410 & 175 & 0.0930 & 29.9 \\
2775 & 60 & $4.9 \mathrm{E} 5$ & 8.3 & 0.69 & -0.03 & 390 & 404 & 222 & 0.101 & 44.5 \\
\hline
\end{tabular}

${ }^{a}$ Boundary layer edge values were estimated from the computational simulations reported in Leidy et al. [14]

Figure 9-3 gives Stanton number maps for these six runs and a comparison laminar run. The Stanton number range differs across the maps to highlight the salient features. The three maps on the left represent the runs where transition first occurs most upstream on the capsule face and elevated heating persists downstream from the point 

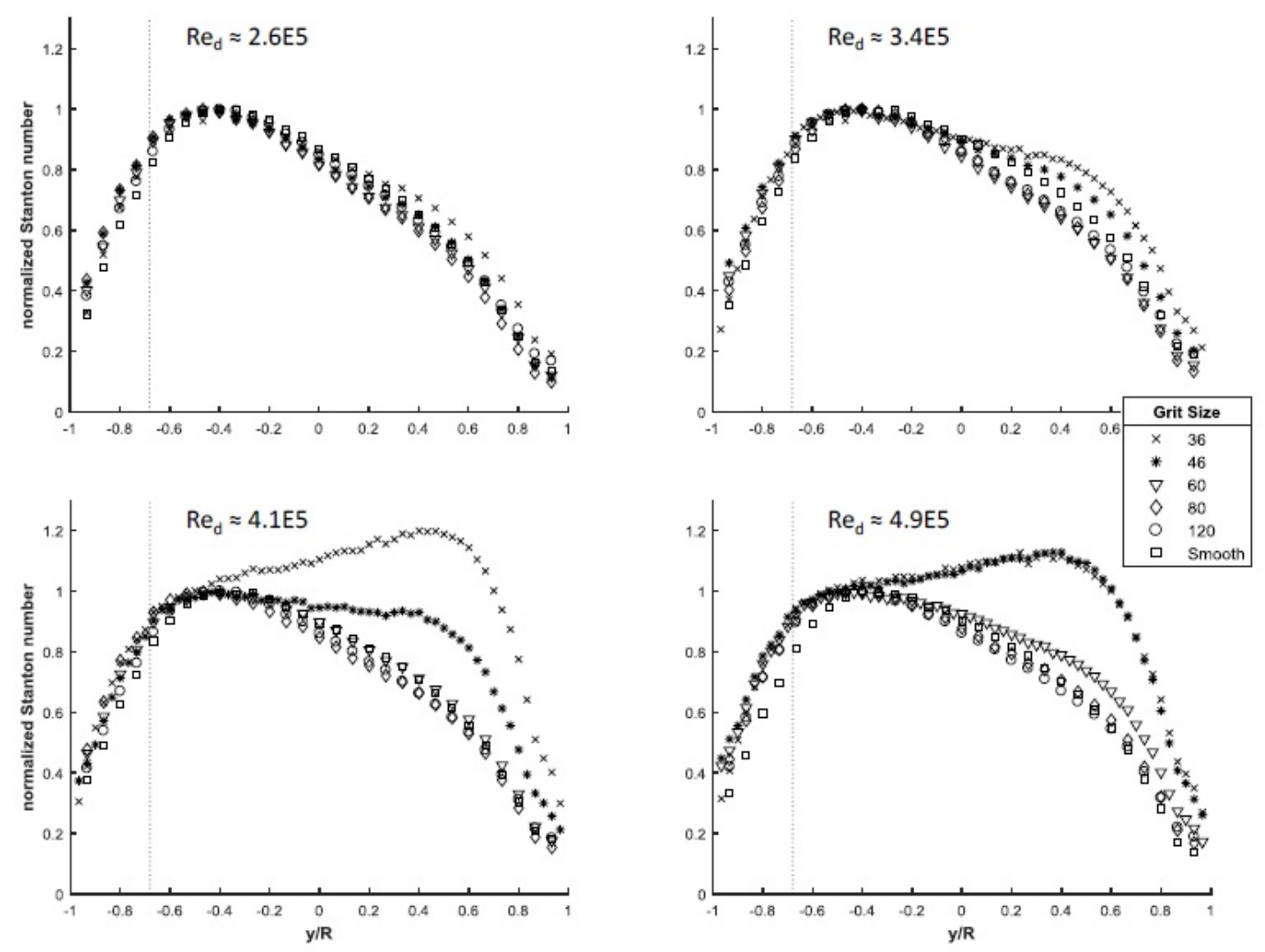

Figure 9-2: Normalized Stanton number plots along the centerline for the entire test matrix

of transition. The Stanton number peaks on the downstream side for all three of these runs. The three maps in the center represent the runs where heating is elevated above the laminar baseline, but transition occurs farther downstream than for the runs shown on the left. The downstream Stanton number for these three runs never exceeds the upstream maximum. The right map corresponds to a run that resulted in only laminar flow. More information on the experimental specifics and detailed results can be found in Leidy et al. [14]. 


\section{EXPERIMENTAL INVESTIGATION OF ROUGHNESS EFFECTS ON TRANSI- TION ON BLUNT SPHERICAL CAPSULE SHAPES}

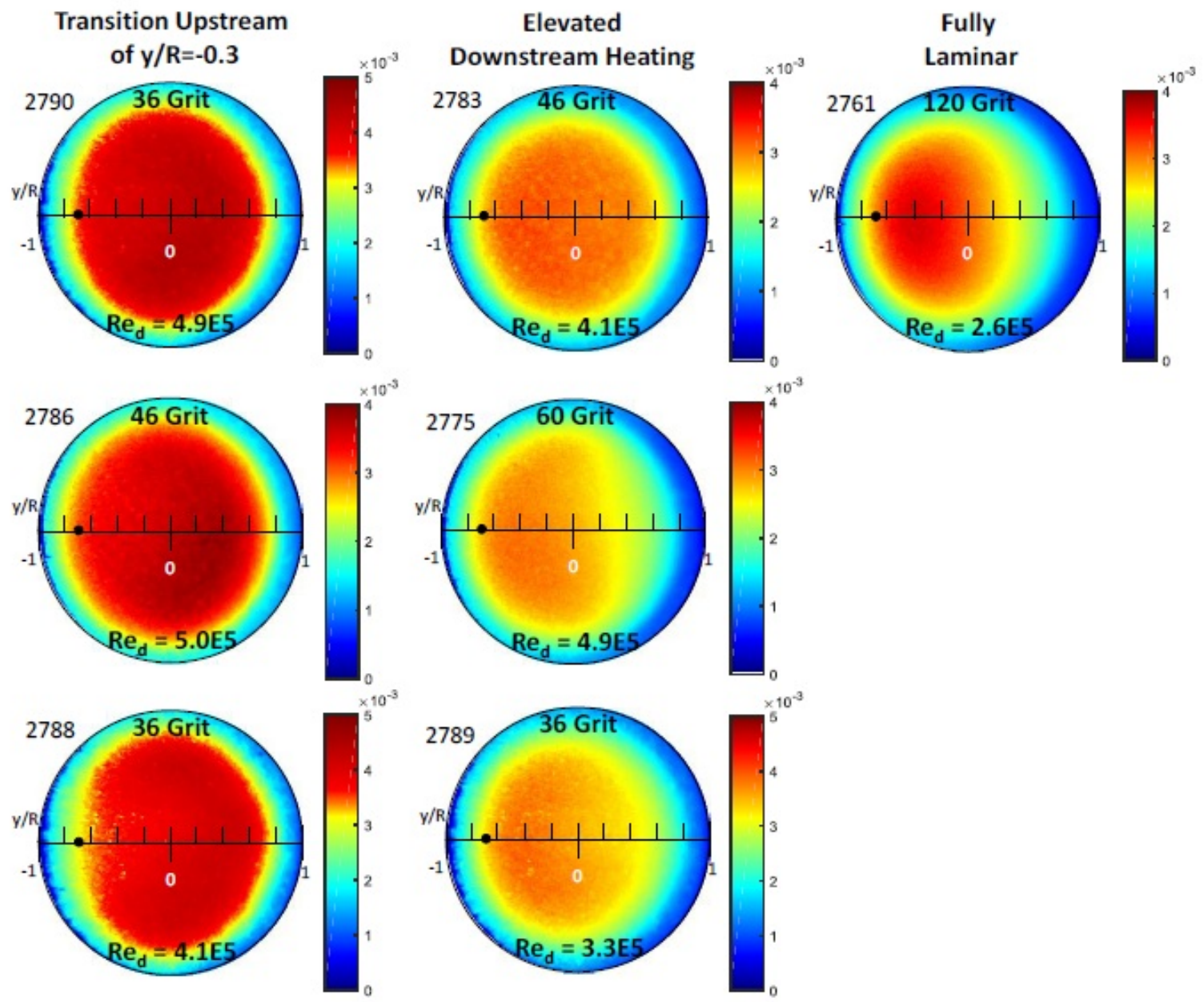

Figure 9-3: Stanton number maps for first to transition (left), other elevated downstream heating (center), and fully laminar (right) cases

\subsection{TRANSITION EXPERIMENTS IN HLB WIND TUNNEL}

\subsubsection{Experimental Setup}

Transition experiments were performed in the hypersonic Ludwieg tube at Technische Universität Braunschweig (HLB). This blow down tunnel was initially calibrated by Estorf et al. [17] and has been used for various experiments of freestream disturbances [18], [19]. The tunnel comprises the partly heated storage tube, the $M a=6$ Laval-nozzle, the test section of $500 \mathrm{~mm}$ in diameter and finally, the dump tank. Before a run, the fast acting valve upstream of the nozzle seals the high-pressure and low pressure parts from each other. Upon valve opening, the high-pressure air expands along the nozzle for about $80 \mathrm{~ms}$, which is the testing time of the tunnel. The unit Reynolds number $(R e / l)$ can be varied between 3-30 $\cdot 10^{6} / \mathrm{m}$. Figure 9-4 displays disturbance level in the test section measured with a stagnation probe, showing the effects of unit-Reynolds number probe position. The data reveal that normalized pitot pressure fluctuation at tunnel axis are the highest for all unit Reynolds numbers. It is believed that the wake of the tunnel valve, mounted centrally in the tunnel settling 
chamber, contributes to the locally increased disturbance level.

The $170 \mathrm{~mm}$ diameter capsule model comprises of a central disc and a movable outer ring. This allows for

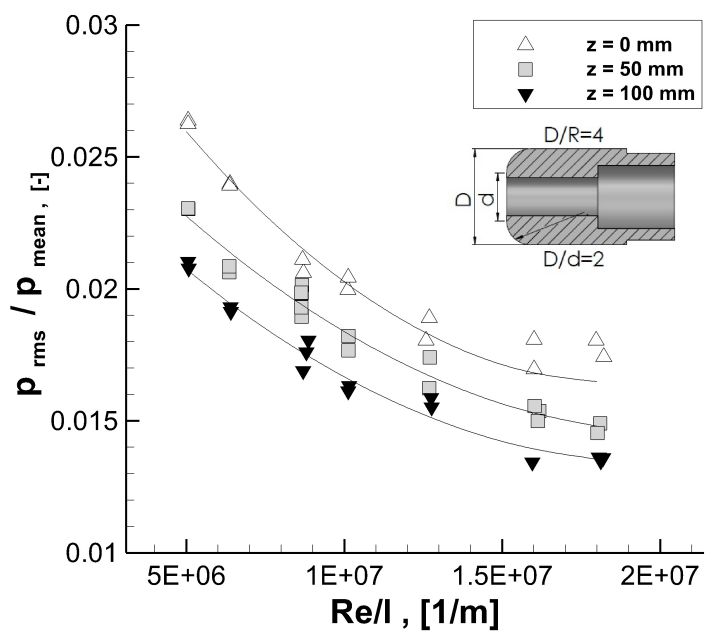

Figure 9-4: Normalized Pitot pressure fluctuation for three z-positions and variation of unit Reynolds number

rotating installed sensors around the model axis, and hence for providing variable space-correlations between sensors. For the present transition experiment, the model was equipped with flush-mounted coaxial thermocouple (TE) sensors in positions that are sketched in Figure 9-5 ( $a$ and b). These sketches show two measurement configurations. In subfigure 9-5 (a), thermocouples are located downstream of a quadratic patch of deterministically arranged and orientated roughness elements (RN). The roughness patch was located at the capsule center. It has a size of $20 \times 20 \mathrm{~mm}$. Another line of TE elements is placed diagonally to the roughness patch, with the same sensor spacing. Note that the sensor P4 was not available in the diagonal configuration. Furthermore, P1, P3 P4 are designed for housing miniature hot-wire inserts, which can be manually adjusted for different wall-normal heights above the capsule surface. Note that the wire supports were glued to the instrumentation holes in order to avoid wire oscillations caused by tunnel startup loads. Subfigure 9-5 (b) displays the setup of stochastically distributed roughness elements as a band over the entire capsule front with 7 thermocouples employed. Subfigure 9-5 (c) and (d) depict the location of the model with respect to the tunnel axis. In the model reference position, the vertical distance between center point of capsule and tunnel axis is $37 \mathrm{~mm}$. In the tunnel axis position, tunnel and model axes coincide.

The subcritical, deterministic roughness patch was manufactured by the Fraunhofer Institute for Surface Engineering and Thin Films, located in Braunschweig, Germany. The institute is capable of producing 3D micrometer-scale surface structures very precisely by applying the technique of photolithography. In the first step, a photoresist is flooded homogenously over the surface. The resist is tempered at $110{ }^{\circ} \mathrm{C}$ for hardening. The resist is then exposed to UV-light while a flexible exposure mask is fixed above the resist. The exposure mask defines the surface roughness arrangement as it provides selective reaction with a developer additive. Eventually, at the positions where the mask shutters the light, one obtains the intended 3D micrometer structures. The final dimensions of the produced cuboidal elements shown in Figure 9-6 displays an edge length of $100 \mu \mathrm{m}$ and the element height is $23 \mu \mathrm{m}$. The equidistant spacing between the elements is also $100 \mu \mathrm{m}$. Figure 9-6 (top) displays a photo of the manufactured roughness patch recorded via laser microscope. Moreover, the line plot in Figure 9-6 displays geometry measurements of a single element. It turns out that quite good agreement between the 


\section{EXPERIMENTAL INVESTIGATION OF ROUGHNESS EFFECTS ON TRANSI- TION ON BLUNT SPHERICAL CAPSULE SHAPES}

(a)

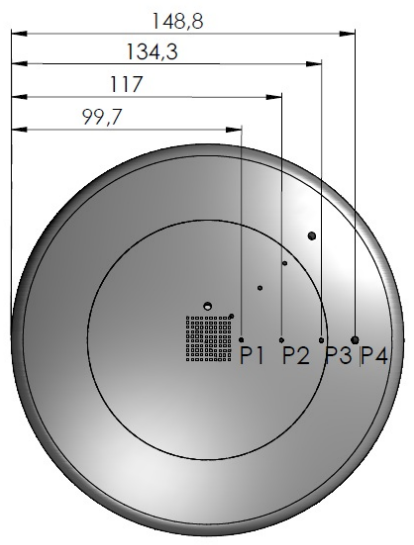

(b)

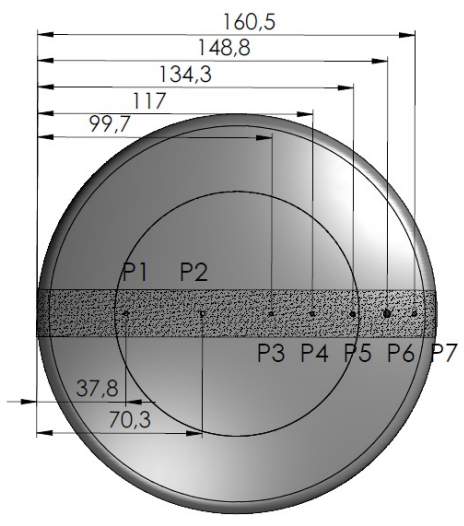

$(\mathrm{c}, \mathrm{d})$

Figure 9-5: Capsule model front with sensor positions for deterministic roughness (a), stochastically distributed roughness (b), and model locations with respect to the tunnel axis at reference (c), and tunnel axis(d).

manufactured elements and design data is achieved.

For investigating roughness induced transition with larger roughness heights, two roughness patches with stochastically arranged elements were prepared. One of them employed spherical particles with a nominal diameter of $100 \mu \mathrm{m}$ made of polyamide (Vestosint(C). The other used angular-shaped metallic particles with a nominal size of $177 \mu \mathrm{m}$. The roughness patches were applied as follows: After putting small covers over the thermocouple sensors, black paint was sprayed on the surface to generate an adhesive layer of almost constant thickness. Next, particles were applied on the adhesive layer from above, by using a trickle device. After paint drying and removal of non-bonded particles, another layer of paint was applied to enclose the particles. Finally, the thermocouple covers were removed and local steps caused by the paint around the sensor recesses as well as along the lateral boundaries of the roughness patch were carefully removed by applying local sanding.

The characteristic heights for both stochastically distributed roughness patches were determined similarly as described in Section 9.2.1 and detailed in Leidy et al [14]. Peak-to-valley heights were derived from surface roughness scans with a laser-microscope system Keyence VK-X100K that allows obtaining window samples with specific dimensions. The surface scans were acquired at three different positions with a size of $1.4 \times 1.4$ $\mathrm{mm}$ for the roughness patch with small particles and at two positions with a size of $3.8 \times 1.0 \mathrm{~mm}$ for the patch with larger particles. Five roughness profiles were extracted in streamline direction from each scan, each covering approximately 5 peaks/valleys for the small-particle samples and 8 peaks/valleys for the samples with large particles. Figure 9-7 presents samples of these profiles. The profiles were manually positioned such that large peak-to-valley values of the scan were precisely captured. The $30 \%$ exceedance criteria [11] was applied on the measured peak-to-valley heights for the data of each scan to obtain numerical $k$-values. Finally, the $k$-values for different surface scans were averaged. As a result, the roughness patch with small particles is characterized by a $k$-value of $99 \mu \mathrm{m}$, whereas the larger particles lead to a $k$-value of $253 \mu \mathrm{m}$. These $k$-values served for extracting roughness Reynolds numbers, $R e_{k k}$, along the roughness patch from Navier-Stokes-solver computation data by DLR-Göttingen [20]. Typically, $R e_{k k}$ increases with unit Reynolds number and streamwise position on the capsule front. Figure 9-8 shows that the deterministic roughness elements are always subcritical. Figure 9-9 displays $R e_{k k}$-values of the two stochastic roughness patches at a moderately high unit Reynolds number. Obviously, by varying Reynolds number and particle size a large variation of $R e_{k k}$-values is possible. Note, that critical values for transition tripping by single roughness elements are in the range $R e_{k k} \approx 400-700$ [21]. 

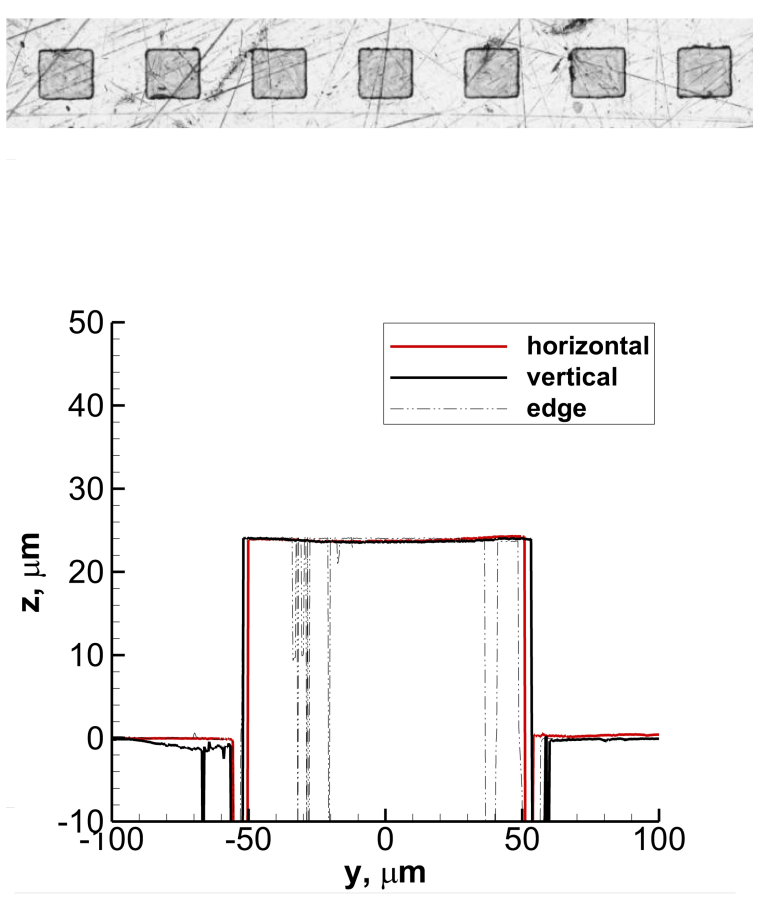

Figure 9-6: Photo of deterministic roughness elements taken by laser microscope and measured size of one single roughness element.
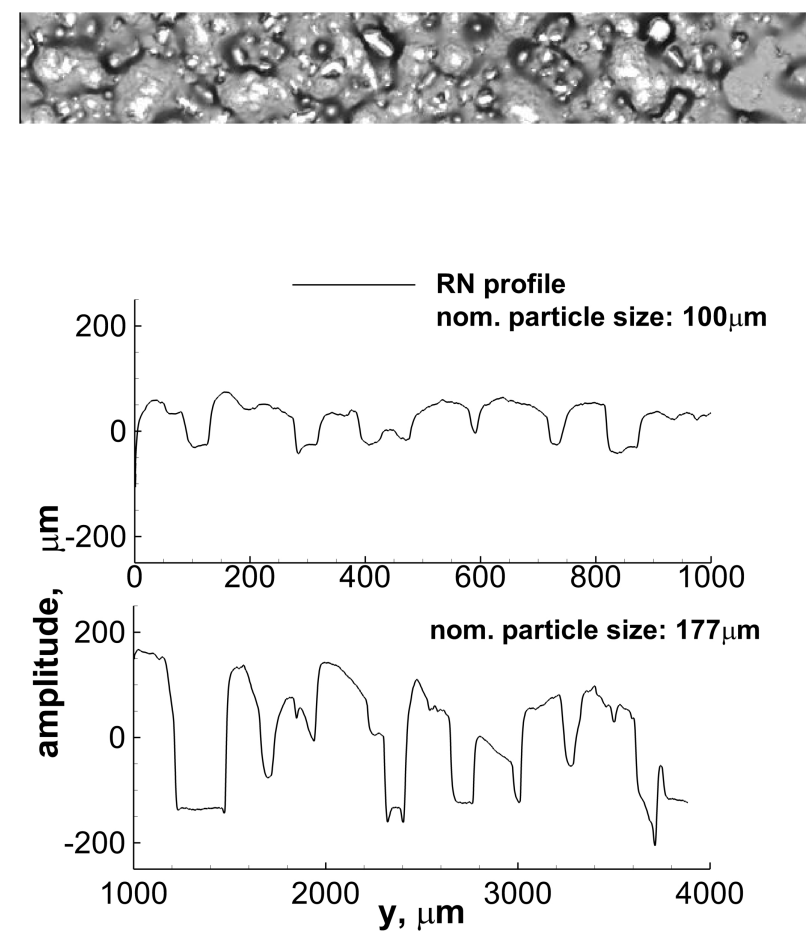

Figure 9-7: Photo of stochastic roughness elements and measured roughness profiles.

\subsubsection{Methods}

Transition experiments were conducted for both capsule locations in the test section, thereby varying the disturbance level of the tunnel freestream relative to the capsule stagnation region. The role of the subcritical, deterministic roughness patch was to represent the surface quality used in previous experiments with non-sanded paint for infrared imaging which had a mean average roughness $\left(R_{a}\right)$ of $10 \mu \mathrm{m}$. Transition experiments with the larger, stochastical roughness served to introduce roughness induced transition on the capsule front.

Transition data were obtained with TE (Type E: chromel-constantan) sensors used to acquire the time signal of the mean surface temperature. A commonly known relation for heat conduction into a semi-infinite slab allows the calculation of the occurring mean heat flux density from the temperature time trace [22]. After completion of TE measurements, hot-wire data were acquired for the cases of the smooth capsule surface and the deterministic roughness, to obtain a more detailed characterization of disturbances within the boundary and in the shock layer close to the boundary layer edge. The high dynamic response of the hot wire system gives access to the fluctuation behavior of disturbances. The hot wire was operated with high overheat ratios, $\tau$, of 0.9 which makes the wire predominately sensitive to massflow, $(\rho u)$. While hot wire raw data for high-speed flows may be decomposed into $\left(T_{o}\right)$ - and $(\rho u)$ - fluctuations [23], this is not valid for the subsonic capsule flow present in the shock layer. We note that only at P4 the flow reached edge Mach numbers larger than one, according to the corresponding flow simulations [20]. Nonetheless, hot wire data contain information on impact of freestream disturbances, effect of subcritical roughness present and finally, on the difference between fluctuations inside the boundary layer and outside the boundary layer edge.

The measurement data were sampled with an M2i.4652 transient recorder (company Spectrum) with a sampling frequency of $3 \mathrm{MHz}$ in 16 bit format. The measured voltage fluctuations via hot wire are displayed as 


\section{EXPERIMENTAL INVESTIGATION OF ROUGHNESS EFFECTS ON TRANSI- TION ON BLUNT SPHERICAL CAPSULE SHAPES}

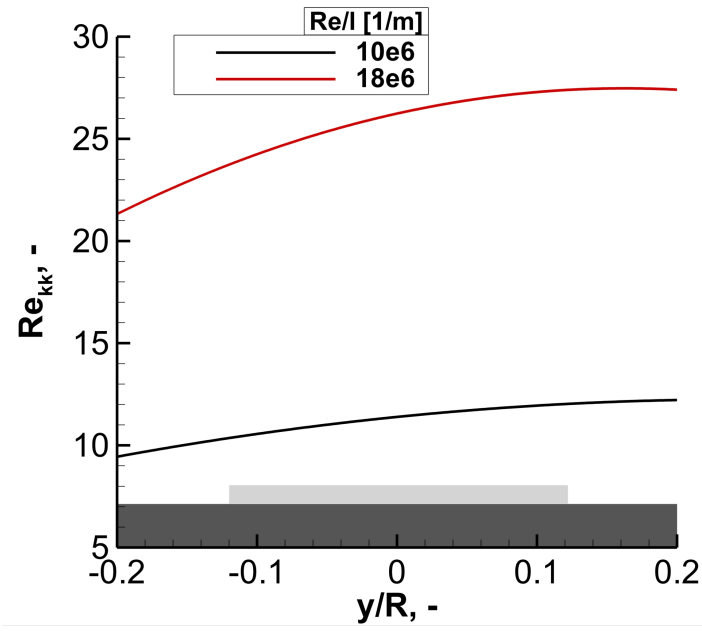

Figure 9-8: $R e_{k k}$ distribution for low and high $R e / l$ case in plane of symmetry of deterministic roughness patch.

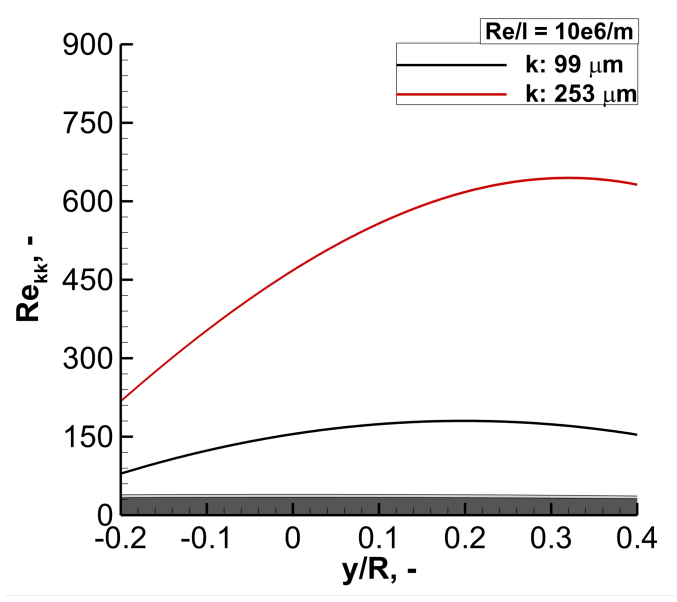

Figure 9-9: $R e_{k k}$ distribution for two $k$-values of stochastic roughness calculated in plane of symmetry.

power spectra density (PSD) obtained by the discrete Fourier transform of the signal. The PSD is based on selected $30 \mathrm{~ms}$ of the sampled data where the flow condition is steady and no sharp spikes in the time trace appear. To improve the quality of the spectra, it was divided into 2048 data points per segment with an overlap of $75 \%$. These segments were multiplied by a normalized Blackman-Harris window to reduce leakage effects and finally averaged over the number of individual spectra. The frequency resolution is then $\Delta f=1,46 \mathrm{kHz}$.

\subsubsection{Results}

In this section the experimental results are presented in two steps. Firstly, the TE data for two tunnel positions are compared for the smooth capsule surface and for the configurations with applied roughness patches. In the second part, hot wire data are presented in form of normalized PSD obtained at position P4.

Figure 9-10 compares the non-dimensional heat flux along the capsule symmetry line for the smooth capsule and for subcritical roughness two with a Navier-Stokes computation at relatively high $R e / l=18 \cdot 10^{6} / \mathrm{m}$. Note, that the stagnation point is located at around $y / R=-0.7$. The infrared (IR) data represent an update of the results reported in Theiss et al. [20]. The mean roughness of the paint for IR measurement was about $3.5 \mu \mathrm{m}$. While the limited field of view of the IR camera did not allow for measuring surface temperatures for $y / R<0.5$, IR data and simulation agree very well on the leeward part of the capsule surface. Also, TE data is displayed for the clean and aligned roughness configurations. For the clean configuration, the TE heat flux is very close to IR data and simulation which indicates an excellent reliability of the experimental methods for heat flux. The blue square elements represent a run with subcritical roughness setup at tunnel axes where for position $\mathrm{P} 4$ transition onset becomes visible.

The evaluation of transition measurements with TE sensors is shown in Figure 9-11 and Figure 9-12. The measurement points without roughness patch (clean) show no sign of transition onset, according to Figure 9-11 (a) and (b). Here, the rows of roughness elements as shown in Figure 9-6 point in streamwise direction which is denoted as aligned roughness. Also, no transition onset is observed for the subcritical roughness patch with the model at the reference position. However, the configuration with subcritical, aligned roughness at tunnel axis in Figure 9-11 (d) generates transition onset for unit Reynolds numbers of $16 \cdot 10^{6} / \mathrm{m}$ and higher. As the sensor 


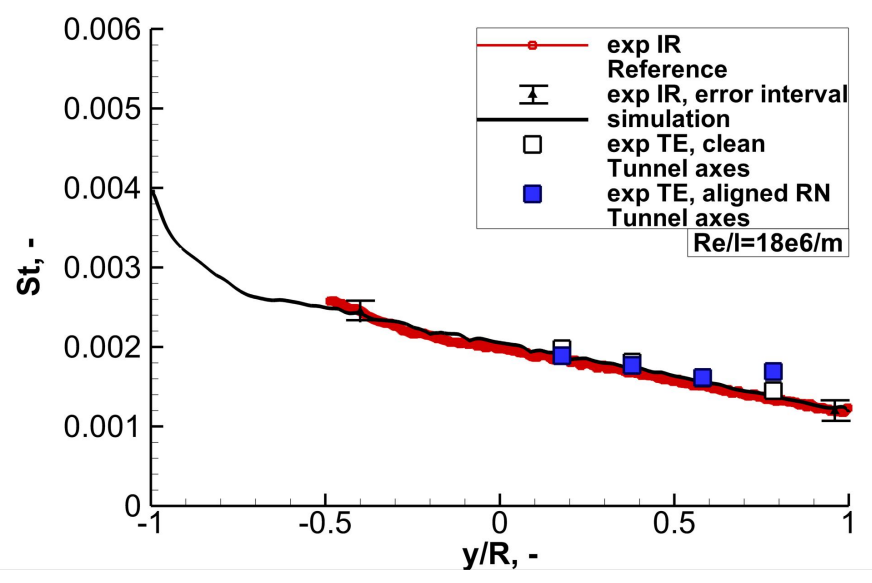

Figure 9-10: Stanton number distribution along symmetry line for clean and subcritical roughness (RN) setup. IR measurement on painted surface of plastic capsule model.

spacing is relatively coarse, transition onset is first observed at $\mathrm{P} 4$ for moderate $R e / l$. At increased Reynolds numbers, transition onset moves upstream as expected. The results show a clear effect of model position on heat flux rise due to transition. Hence, this transition phenomenon cannot not be characterized as roughness induced transition, since freestream disturbances contribute to the transition process as well. At this point we characterize the phenomenon as roughness augmented transition.

Transition results with the patches of stochastical roughness elements are shown in Figure 9-12 (a-c). Heat flux data obtained with the smaller roughness height, $k=99 \mu \mathrm{m}$, indicate first transition onset for a unit Reynolds number of $6.25 \cdot 10^{6} / \mathrm{m}$. Transition onset moves upstream with increasing $R e / l$, as seen in subfigure 9-12 (a). At $R e / l$ of $12.5 \cdot 10^{6} / \mathrm{m}$, the high heat flux values obtained at the most downstream measurement positions indicate a fully turbulent boundary layer. Subfigure 9-12 (b) presents samples of heat flux results for the roughness patch with larger roughness height, $k=253 \mu \mathrm{m}$. Transition onset occurs on the capsule luv side, even at the lowest unit Reynolds number. Note that the highest Reynolds number, at which transition onset can be resolved for $k=253 \mu \mathrm{m}$ with the present location of thermocouples, is about $10 \cdot 10^{6} / \mathrm{m}$. Subfigure 9-12 (c) displays the effect of capsule position in the wind tunnel and hence, the effect of freestream disturbances on boundary layer transition. This yields evidence that the observed transition onset is dominated by roughness since the capsule position appears to have little effect on the heat flux.

The extraction of a precise location of transition onset from the measured sets of discrete heat flux data appeared as a particular challenge. Closer inspection of the data points in subfigures 9-12 (a,b) reveal that information about the assumed region of transition onset is typically contained in the heat flux data of three sensors, one representing still laminar flow and two indicating the transitional rise of heat flux. The numerical extraction process is complicated by the fact that the thermocouple reading of laminar heat flux at the rough surface carries some additional scatter relative to the smooth surface, as the sensor is located in a small recess of the roughness layer. One way to reduce uncertainty due to the scatter of the laminar reading is to introduce additional data form numerical flow simulations. Therefore, a number of 12 additional data points along an arc length of $10 \%$ of the capsule diameter, located just upstream of the assumed laminar sensor, were extracted from the numerical flow solution, to represent the laminar flow better. Then a polynomial best fit was applied on the new data set that now included the heat flux of 12 numerical simulation points and the three thermocouple results. To determine 


\section{EXPERIMENTAL INVESTIGATION OF ROUGHNESS EFFECTS ON TRANSI- TION ON BLUNT SPHERICAL CAPSULE SHAPES}

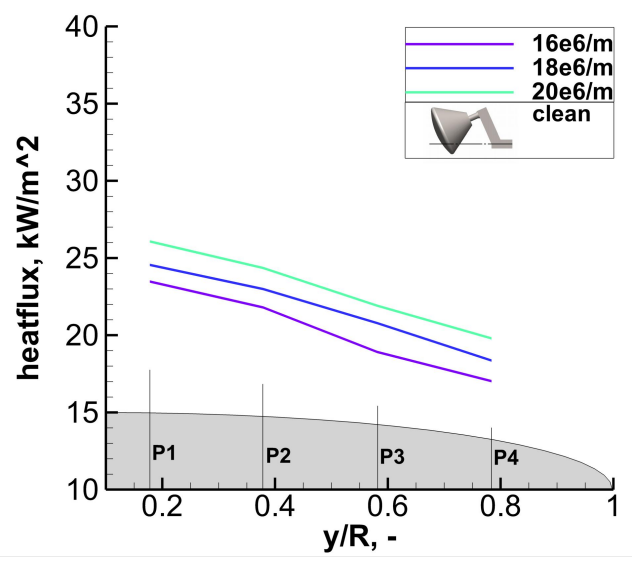

(a)

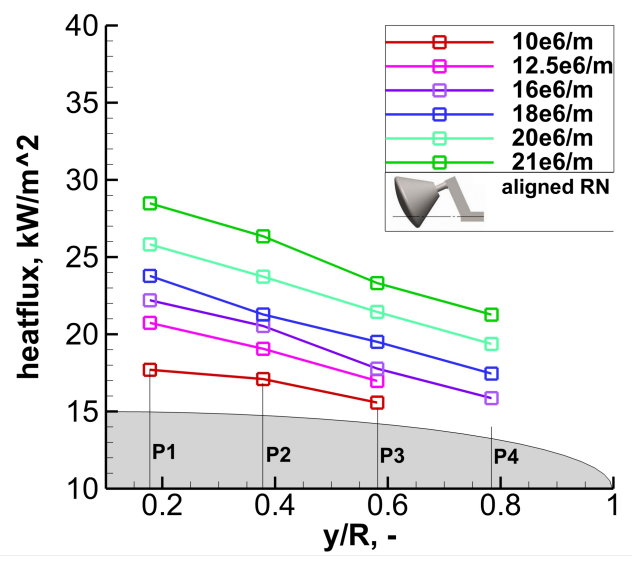

(c)

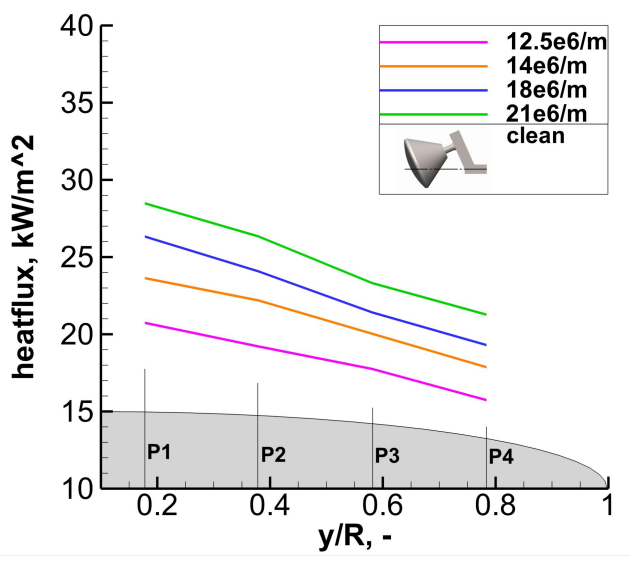

(b)

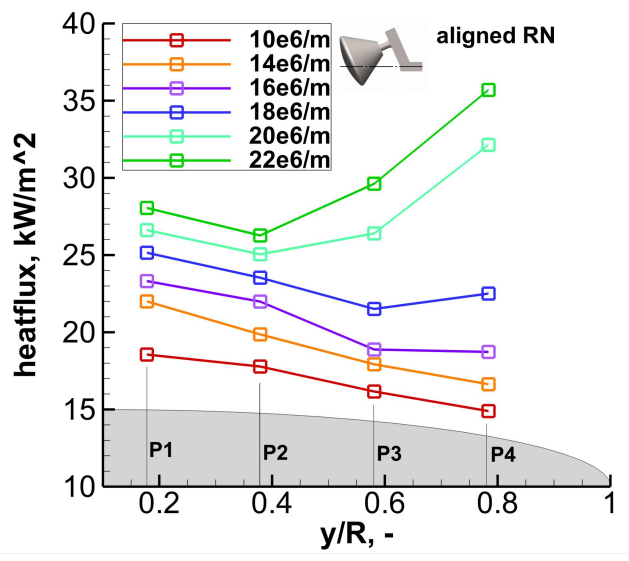

(d)

Figure 9-11: Heat fluxes on smooth surface (a,b) and with subcritical, roughness, $k=23 \mu \mathrm{m}$ (c,d).

location of transition onset, a $5 \%$ deviation criteria was applied to the difference between the simulation curve and the polynomial curve.

Hot wire measurements constituted the second part of the investigations. For this purpose the capsule was instrumented with a hot wire at the position P4 of Figure 9-6 (a). The hot wire signal is presented in form of normalized PSD spectra. The capsule model was positioned at tunnel axis, where the thermocouple measurements showed transition onset at the sensor location $\mathrm{P} 4$ for $R e / l=16 \cdot 10^{6} / \mathrm{m}$, with the subcritical roughness patch. Voltage fluctuations were normalized with the mean voltage of the hot wire system during the selected test interval. Figure 9-13 illustrates the obtained spectra for clean surface and with subcritical, deterministic roughness, measured within the boundary layer at $0.5 \mathrm{~mm}$ above the surface. Until $100 \mathrm{kHz}$ both spectra appear very similar. The spectrum of the clean surface drops smoothly beyond that frequency until it vanishes in electronical noise at about $200 \mathrm{kHz}$. On the contrary, three broadband peaks of fluctuation appear in the frequency ranges of $100-140 \mathrm{kHz}, 140-180 \mathrm{kHz}$ and $220-250 \mathrm{kHz}$. The first two peaks exhibit a moderate Reynolds-number dependency as seen in Figure 9-15, whereas the high-frequency peak is insensitive to $R e / l$ changes. At this 


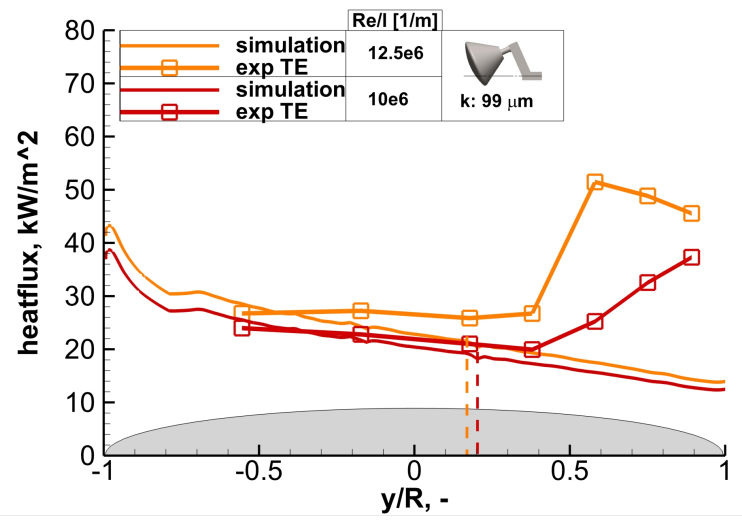

(a)

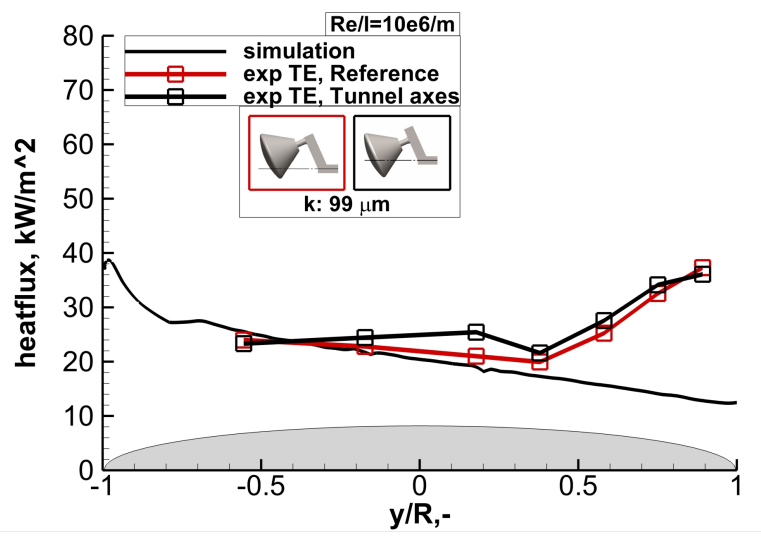

(c)

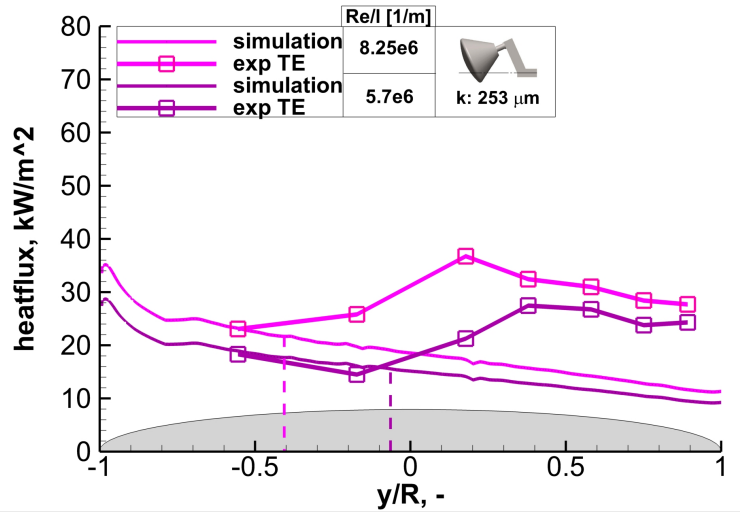

(b)

Figure 9-12: Heat fluxes with stochastic roughness, $k=99 \mu \mathrm{m}(\mathrm{a}), k=253 \mu \mathrm{m}(\mathrm{b})$, and tunnel position variation for $k=99 \mu \mathrm{m}(\mathrm{c})$.

point, no statement can be made, whether the first two peaks are physically connected, as they appear to overlap around $140 \mathrm{kHz}$. The shape of the fluctuation peaks indicates broadening with Reynolds number. We speculate that the high-frequency peaks represent roughness-induced fluctuations of vortical structures within the boundary layer. The vortical structures develop from vorticity modes of the freestream, subject to strong acceleration downstream the stagnation point. Further hot-wire data analysis should also characterize signal behaviors in transitional flows at higher Reynolds numbers, by extracting the possible growth of turbulent spots.

Hot-wire data obtained in the shock layer $1.5 \mathrm{~mm}$ away from the wall are compared to boundary layer data as shown in Figure 9-14, for one exemplary run at $R e / l=12.5 \cdot 10^{6} / \mathrm{m}$. The measured fluctuations start to differ from $20 \mathrm{kHz}$ on, where the boundary-layer spectra show higher fluctuations. Furthermore, one observes only two broad-band peaks in the shock layer, which are smaller than the peaks in the boundary layer. These peaks of the shock layer show little effect of the Reynolds number on peak frequency, while some spectral broadening also occurs, according to Figure 9-16. Future repeated measurements should be used to confirm these findings and provide high-frequency disturbances at further measurement points in the capsule flow field. 


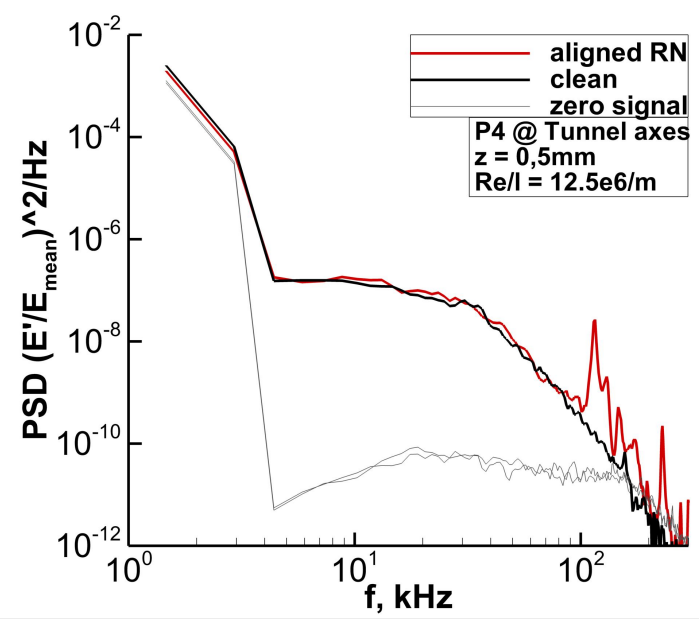

Figure 9-13: PSD of hot wire signal, comparing clean versus subcritical roughness patch configuration

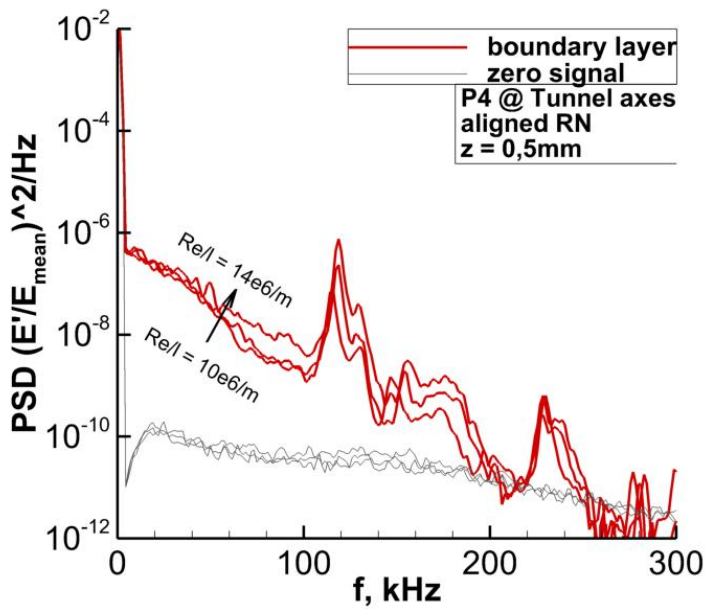

Figure 9-15: PSD of hot wire signal obtained in boundary layer, variation of $R e / l$

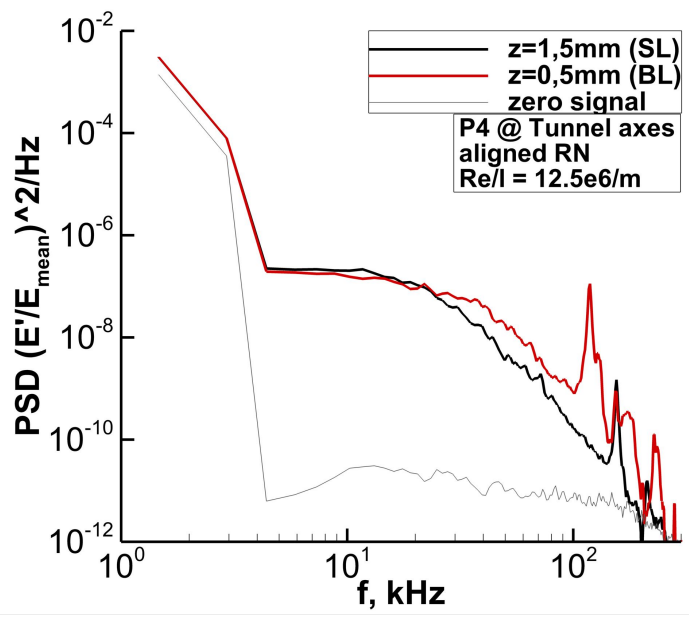

Figure 9-14: PSD of hot wire signal, comparing BL and SL position

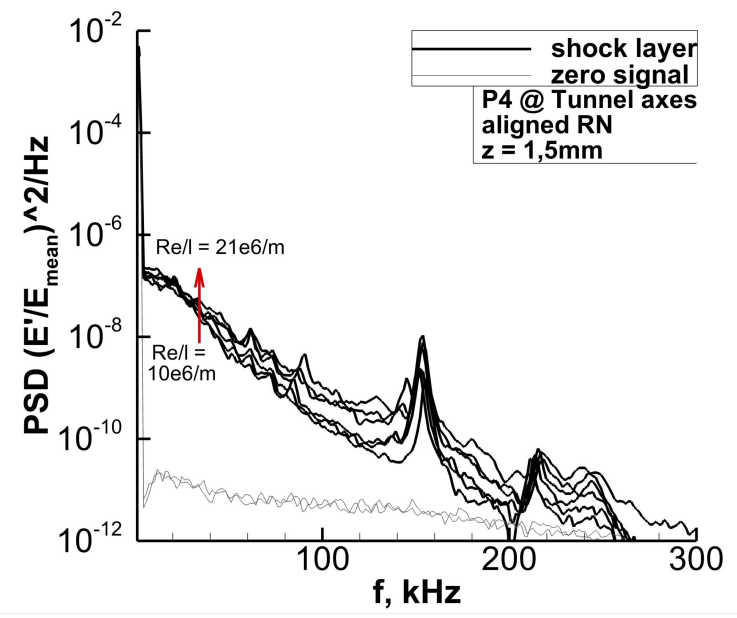

Figure 9-16: PSD of hot wire signal obtained in shock layer, variation of $R e / l$

\subsection{TRANSITION EXPERIMENTS IN HIEST FACILITY}

An aeroheating measurement test campaign on a capsule model with laminar and turbulent boundary layers was performed in the free-piston shock tunnel JAXA-HIEST [24]. A $250 \mathrm{~mm}$-diameter $6.4 \%$-scale Apollo CM capsule model was used. To measure heat flux distribution, the model was equipped with miniature co-axial chromel-constantan thermocouples on its heat shield surface. In order to promote boundary layer transition, a boundary layer trip insert with 'pizza box' shaped isolated roughness elements of variable height was employed. 
Heat flux records with and without roughness elements were obtained for a 28 deg angle of attack under stagnation enthalpies from $H_{0}=3.6 \mathrm{MJ} / \mathrm{kg}$ to $21 \mathrm{MJ} / \mathrm{kg}$ and stagnation pressures from $P_{0}=27 \mathrm{MPa}$ to $52 \mathrm{MPa}$. Under these conditions, the unit Reynolds number varied from $0.84-4.8 \cdot 10^{6} / \mathrm{m}$.
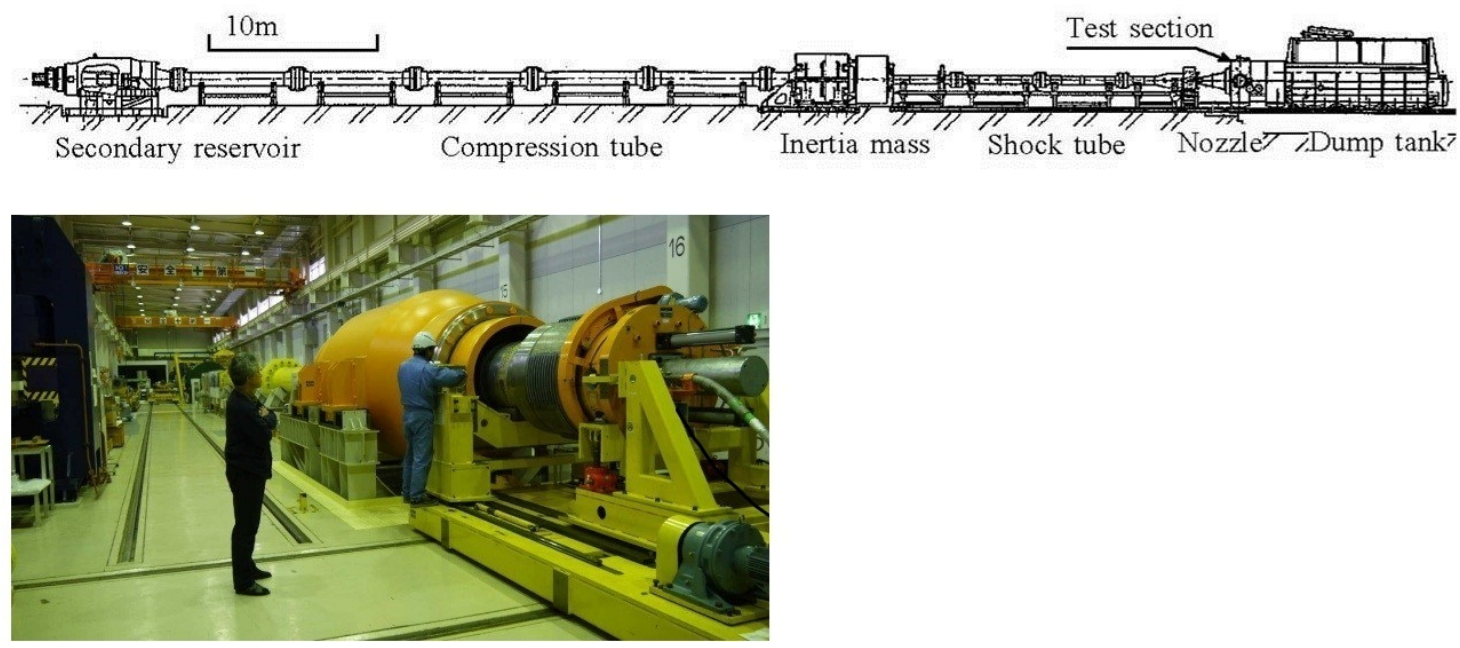

Figure 9-17: Free-piston shock tunnel HIEST

\subsubsection{Experimental Setup}

Figure 9-17 presents the layout and picture of the free-piston shock tunnel HIEST. This tunnel was originally built to obtain the aerothermodynamic characteristics of the Japanese reentry vehicle HOPE. The tunnel can produce higher stagnation conditions and longer test times than any other free-piston facility because it was originally designed to operate in a 'tuned' condition [25]. The tunnel can be operated at stagnation pressures $P_{0}$ up to $150 \mathrm{MPa}$ and stagnation enthalpies $H_{0}$ up to $25 \mathrm{MJ} / \mathrm{kg}$ with test times of $2 \mathrm{~ms}$ or longer. In the present test campaign, the HIEST contoured nozzle was used, which is $2.8 \mathrm{~m}$ long and has an exit diameter of $800 \mathrm{~mm}$. Nozzle flow calibration was discussed in a previous report [26]. From $H_{0}=3.5 \mathrm{MJ} / \mathrm{kg}$ to $20 \mathrm{MJ} / \mathrm{kg}$, the nozzle calibration tests showed that a steady test core flow diameter prevails up to $400 \mathrm{~mm}$, in which the deviation of the free-stream Pitot pressure is less than $6 \%$. Since the test duration depends on the stagnation condition, the test duration is $7 \mathrm{~ms}$ or longer in low-enthalpy conditions $\left(H_{0}=3.5 \mathrm{MJ} / \mathrm{kg}\right.$ or lower). The relation between the free-stream $R e$ number and the stagnation enthalpy with the HIEST contoured nozzle is shown in Figure 9-18. 


\section{EXPERIMENTAL INVESTIGATION OF ROUGHNESS EFFECTS ON TRANSI- TION ON BLUNT SPHERICAL CAPSULE SHAPES}

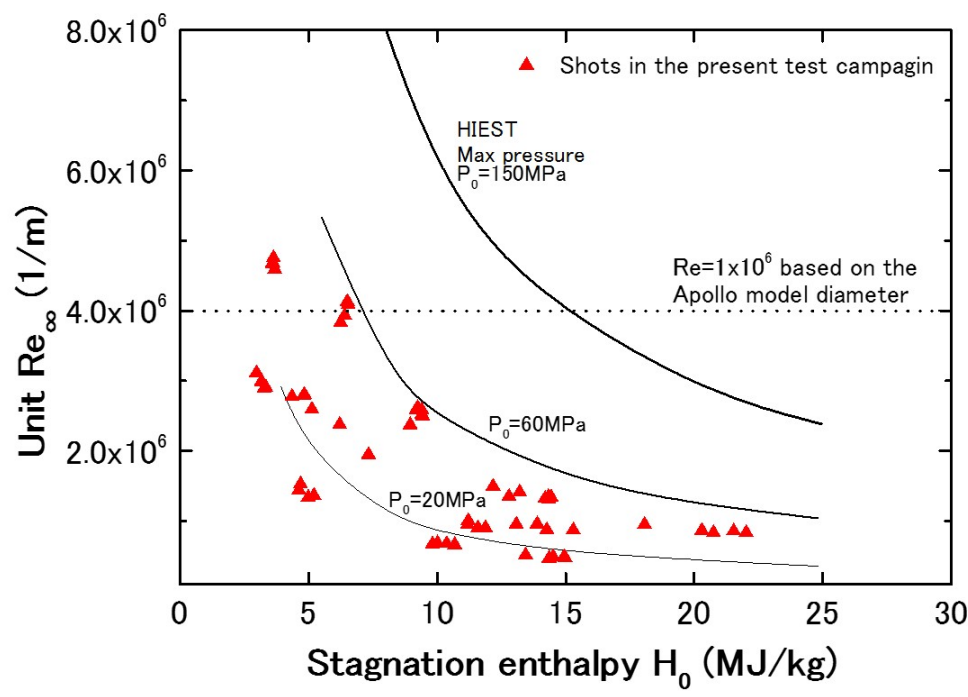

Figure 9-18: Unit Reynolds number and stagnation enthalpy in the present test campaign.

Table 9-3: Free-stream condition

\begin{tabular}{cccccccccc}
\hline \hline $\begin{array}{c}\text { Condition } \\
-\end{array}$ & $\begin{array}{c}\mathrm{P}_{0} \\
(M P a)\end{array}$ & $\begin{array}{c}\mathrm{H}_{0} \\
(M J / k g)\end{array}$ & $\begin{array}{c}\mathrm{T}_{0} \\
(K)\end{array}$ & $\begin{array}{c}\mathrm{T}_{\infty} \\
(K)\end{array}$ & $\begin{array}{c}\mathrm{P}_{\infty} \\
(k P a)\end{array}$ & $\begin{array}{c}\rho_{\infty} \\
\left(k g / m^{3}\right)\end{array}$ & $\begin{array}{c}\mathrm{U}_{\infty} \\
(m / s)\end{array}$ & $\begin{array}{c}\mathrm{Ma}_{\infty} \\
-\end{array}$ & $\begin{array}{c}\mathrm{Re} / 1 \\
-\end{array}$ \\
\hline$A$ & $3.1 \mathrm{E} 1$ & 3.6 & $3.0 \mathrm{E} 3$ & $2.7 \mathrm{E} 2$ & 2.5 & $3.2 \mathrm{E}-2$ & 2.5 & 7.7 & $4.8 \mathrm{E} 6$ \\
$B$ & $2.7 \mathrm{E} 1$ & 5.1 & $3.9 \mathrm{E} 3$ & $4.4 \mathrm{E} 2$ & 2.6 & $2.1 \mathrm{E}-2$ & 3.0 & 7.2 & $2.6 \mathrm{E} 6$ \\
$C$ & $5.2 \mathrm{E} 1$ & 6.3 & $4.5 \mathrm{E} 3$ & $5.8 \mathrm{E} 2$ & 5.8 & $3.4 \mathrm{E}-2$ & 3.3 & 6.9 & $3.8 \mathrm{E} 6$ \\
$D$ & $5.2 \mathrm{E} 1$ & 9.0 & $5.7 \mathrm{E} 3$ & $9.6 \mathrm{E} 2$ & 7.1 & $2.5 \mathrm{E}-2$ & 3.9 & 6.4 & $2.4 \mathrm{E} 6$ \\
$E$ & $4.3 \mathrm{E} 1$ & $1.3 \mathrm{E} 1$ & $7.1 \mathrm{E} 3$ & $1.4 \mathrm{E} 3$ & 6.5 & $1.6 \mathrm{E}-2$ & 4.6 & 6.1 & $1.4 \mathrm{E} 6$ \\
$F$ & $8.3 \mathrm{E} 1$ & $1.3 \mathrm{E} 1$ & $7.3 \mathrm{E} 3$ & $1.4 \mathrm{E} 3$ & 12.6 & $2.9 \mathrm{E}-2$ & 4.6 & 5.9 & $2.4 \mathrm{E} 6$ \\
$G$ & $4.2 \mathrm{E} 1$ & $2.1 \mathrm{E} 1$ & $9.0 \mathrm{E} 3$ & $2.0 \mathrm{E} 3$ & 6.7 & $1.0 \mathrm{E}-2$ & 5.6 & 6.0 & $8.4 \mathrm{E} 5$ \\
\hline
\end{tabular}

\subsubsection{Methods}

The diameter of the Apollo CM test model used in the test campaign was $250 \mathrm{~mm}$, which is almost $6.4 \%$ of the actual flight vehicle (Figure 9-19). On the windward surface of the model, 88 co-axial miniature thermocouples were mounted, and 12 co-axial miniature thermocouples and two Kulite Piezoresistive pressure transducers were mounted on the leeward surface (not shown in the figure). The thermocouples, originally developed at CalTech [27], [28], were chromel-constantan with a diameter of $2.0 \mathrm{~mm}$ (Figure 9-22). The left-hand picture in Figure 9-20 shows the heat shield surface of the Apollo CM test model. Coaxial thermocouples are displayed as dots on the surface. The other picture in Figure 9-20 presents the model installation in the HIEST test section with 28 deg angle of attack. To monitor the test free-stream, there are two permanent probes (Pitot pressure probe and heat flux probe) in the HIEST test section. Both of the two permanent probes are located $250 \mathrm{~mm}$ from the nozzle center.

For the present test campaign, natural boundary layer transition was not expected, except for the lowest enthalpy condition. The isolated roughness element was therefore required to promote boundary layer transition on the lee side of the heat shield (Figure 9-21). The roughness elements used were 'pizza box' shaped isolated 


\section{EXPERIMENTAL INVESTIGATION OF ROUGHNESS EFFECTS ON TRANSITION ON BLUNT SPHERICAL CAPSULE SHAPES}
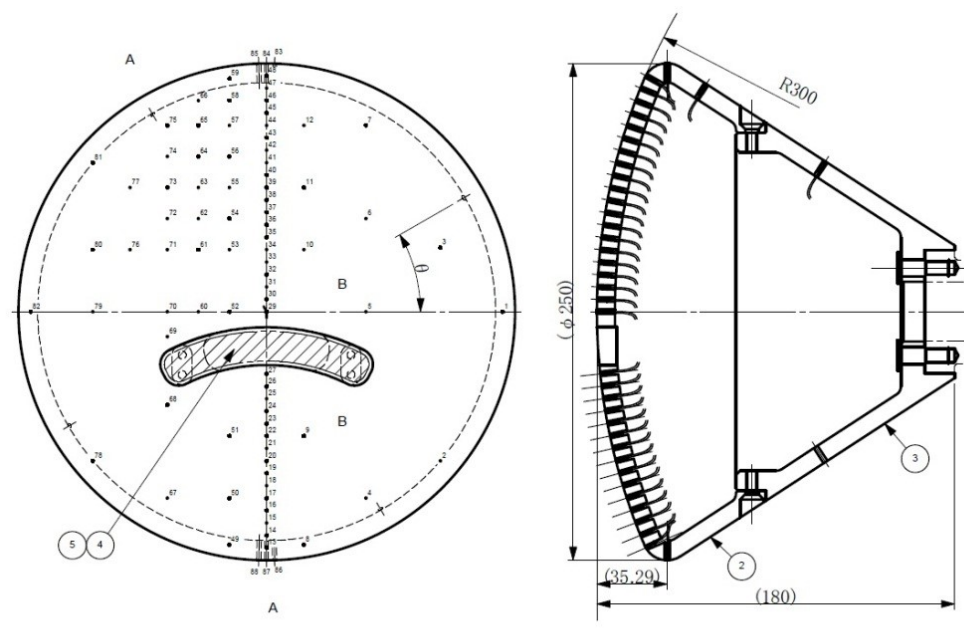

Figure 9-19: Drawing of the Apollo CM-AS202 test model, denoting thermocouples locations as dots (left).

Table 9-4: Flow condition at the trip insert $T_{w}=300 \mathrm{~K}$ (const.)

\begin{tabular}{ccccccccccc}
\hline \hline $\begin{array}{c}\text { Condition } \\
-\end{array}$ & $\mathrm{T}_{e}$ & $\mathrm{H}_{w}$ & $\mathrm{H}_{e}$ & $\mathrm{Ma}_{e}$ & $\delta$ & $\theta$ & $\mathrm{Re}_{\theta}$ & $\mathrm{Re}_{k k}$ & $\mathrm{Re}_{k k}$ & $\mathrm{Re}_{k k}$ \\
$(J)$ & $(J g)$ & $(J / K g)$ & $(-)$ & $(m)$ & $(m)$ & - & $0.3 m m$ & $0.6 m m$ & $0.8 m m$ \\
\hline$A$ & $3.0 \mathrm{E} 3$ & $4.9 \mathrm{E} 5$ & $4.1 \mathrm{E} 6$ & $5.2 \mathrm{E}-1$ & $6.4 \mathrm{E}-4$ & $1.1 \mathrm{E}-4$ & $1.2 \mathrm{E} 2$ & $3.4 \mathrm{E} 2$ & $6.1 \mathrm{E} 2$ & $8.1 \mathrm{E} 2$ \\
$B$ & $3.3 \mathrm{E} 3$ & $5.6 \mathrm{E} 5$ & $5.1 \mathrm{E} 6$ & $5.3 \mathrm{E}-1$ & $8.7 \mathrm{E}-4$ & $1.3 \mathrm{E}-4$ & $1.1 \mathrm{E} 2$ & $3.0 \mathrm{E} 2$ & $5.3 \mathrm{E} 2$ & $6.9 \mathrm{E} 2$ \\
$C$ & $3.7 \mathrm{E} 3$ & $5.3 \mathrm{E} 5$ & $6.2 \mathrm{E} 6$ & $5.3 \mathrm{E}-1$ & $6.9 \mathrm{E}-4$ & $9.7 \mathrm{E}-4$ & $1.5 \mathrm{E} 2$ & $4.9 \mathrm{E} 2$ & $9.0 \mathrm{E} 2$ & $1.2 \mathrm{E} 3$ \\
$D$ & $4.5 \mathrm{E} 3$ & $5.7 \mathrm{E} 5$ & $8.8 \mathrm{E} 6$ & $5.3 \mathrm{E}-1$ & $7.6 \mathrm{E}-4$ & $1.1 \mathrm{E}-4$ & $1.8 \mathrm{E} 2$ & $4.2 \mathrm{E} 2$ & $7.3 \mathrm{E} 2$ & $9.5 \mathrm{E} 2$ \\
$E$ & $5.7 \mathrm{E} 3$ & $6.7 \mathrm{E} 5$ & $1.3 \mathrm{E} 7$ & $5.3 \mathrm{E}-1$ & $9.3 \mathrm{E}-4$ & $1.5 \mathrm{E}-4$ & $1.1 \mathrm{E} 2$ & $2.7 \mathrm{E} 2$ & $4.6 \mathrm{E} 2$ & $5.9 \mathrm{E} 2$ \\
$F$ & $5.9 \mathrm{E} 3$ & $5.7 \mathrm{E} 5$ & $1.2 \mathrm{E} 7$ & $5.3 \mathrm{E}-1$ & $6.8 \mathrm{E}-4$ & $1.1 \mathrm{E}-4$ & $1.5 \mathrm{E} 2$ & $4.7 \mathrm{E} 2$ & $8.3 \mathrm{E} 2$ & $1.1 \mathrm{E} 3$ \\
$G$ & $6.8 \mathrm{E} 3$ & $7.9 \mathrm{E} 5$ & $2.1 \mathrm{E} 7$ & $5.3 \mathrm{E}-1$ & $1.1 \mathrm{E}-3$ & $1.7 \mathrm{E}-4$ & $9.4 \mathrm{E} 1$ & $1.9 \mathrm{E} 2$ & $3.5 \mathrm{E} 2$ & $4.6 \mathrm{E} 2$ \\
\hline
\end{tabular}

roughness elements, which were used in several wind tunnel tests for CEV Orion development [29], [30]. The boundary layer thickness on the model heat shield surface was calculated for the test flow conditions by numerical simulations performed at NASA JSC [31]. The roughness height was determined to $k=0.2,0.3,0.6,0.8$, 1.1 and $1.3 \mathrm{~mm}$ according to the calculations. In the present test campaign, roughness heights of $k=0.3,0.6$ and $1.1 \mathrm{~mm}$ were used. All the roughness elements were machined on a trip insert made from copper alloy to prevent damage from aeroheating, and inserts were located $17 \mathrm{~mm}(z / D=0.068)$ below the model's geometric centerline on its heat shield surface, a location that was also determined using data from a previous study. 

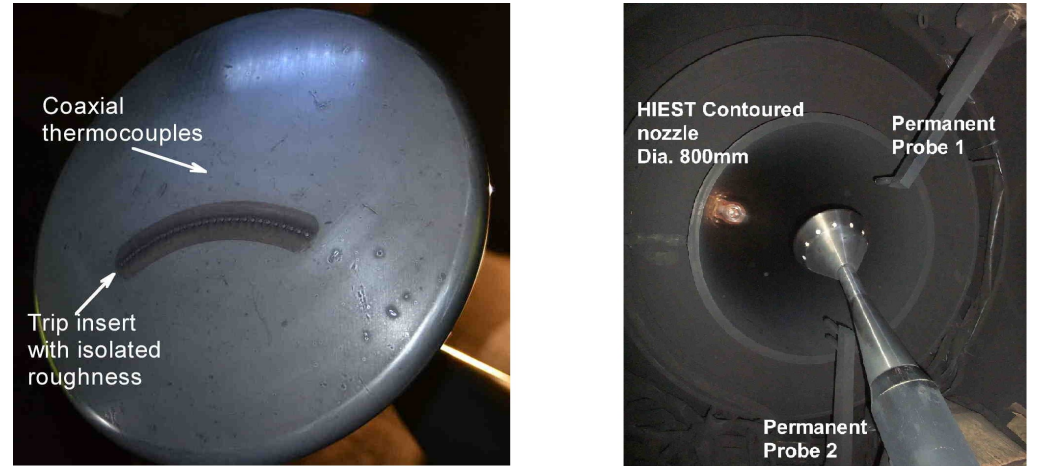

Figure 9-20: Apollo model with 'pizza box' shaped isolated roughness elements $(k=0.3 \mathrm{~mm})$ and model installation in HIEST test section.

\subsubsection{Results}

In HIEST, stagnation conditions in the nozzle reservoir (shock tube end) were calculated with an equilibrium computation code [32] from the shock speed and the shock tube initial conditions. For the stagnation condition, the free-stream condition was calculated with an axis-symmetrical JAXA in-house nozzle flow code [33]. Table 9-3 and Table 9-4 show all the free-stream conditions and flow condition at the trip insert, respectively.

Since heat flux measurements varied remarkably with $H_{0}$ and $P_{0}$ due to an unexpected heat flux augmentation [20], they cannot be directly compared with the results obtained under different flow conditions. Therefore, smooth surfaces (i.e. the trip insert without roughness elements) were also tested under each test condition to obtain reference heat flux distributions. As already shown in Figure 9-18, even when limited to low-enthalpy conditions, HIEST can produce Reynolds numbers sufficiently high to reach the onset of natural transition without any roughness elements. Figure 9-23 (a) shows a comparison between natural (smooth surface) and forced transition (roughness of $k=0.6 \mathrm{~mm})$ measured at the lowest enthalpy under medium-pressure conditions $\left(H_{0}=\right.$ $3.6 \mathrm{MJ} / \mathrm{kg}, P_{0}=31 \mathrm{MPa}$ ), at which the unit Reynolds number was $4.8 \cdot 10^{6} / \mathrm{m}$. Here, the variable $z / D$ denotes the radial coordinate in the symmetry plane.

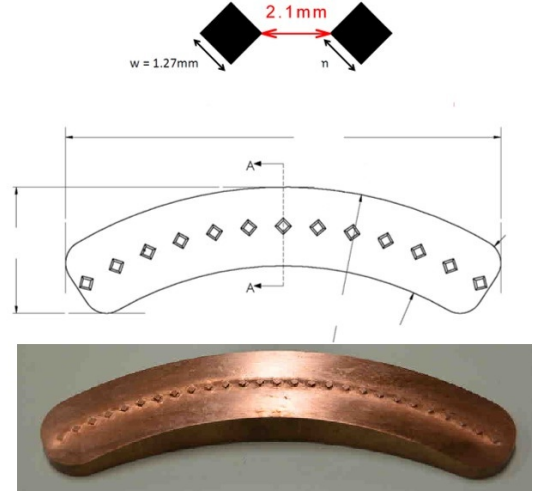

Figure 9-21: 'Pizza box' shaped isolated roughness elements and a trip insert with 13 roughness elements $(k=0.8 \mathrm{~mm})$.

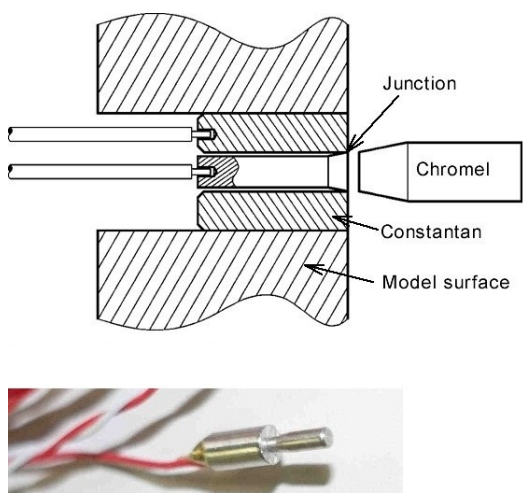

Figure 9-22: Cross section of the coaxial miniature thermocouple with $2 \mathrm{~mm}$ diameter and a photo. 


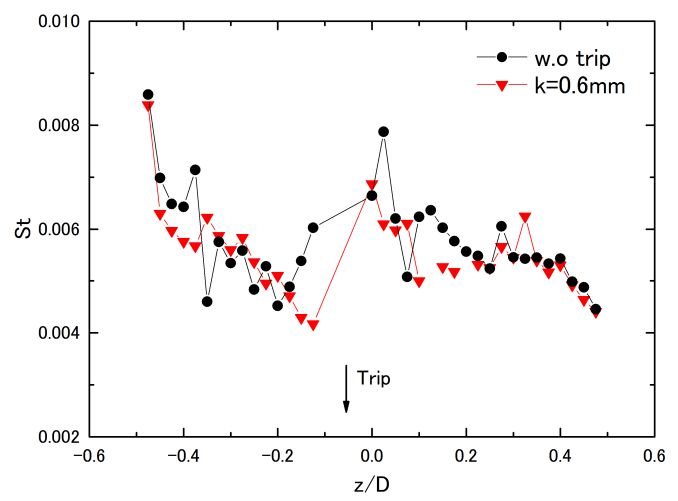

(a) Condition A: $H_{0}=3.6 \mathrm{MJ} / \mathrm{kg}, R e / l=4.8 \mathrm{E} 6 / \mathrm{m}$

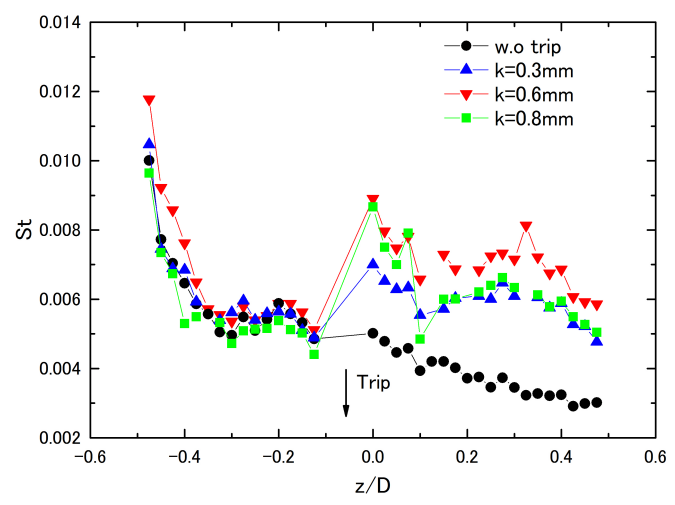

(c) Condition C: $H_{0}=6.3 \mathrm{MJ} / \mathrm{kg}, R e / l=3.8 \mathrm{E} 6 / \mathrm{m}$

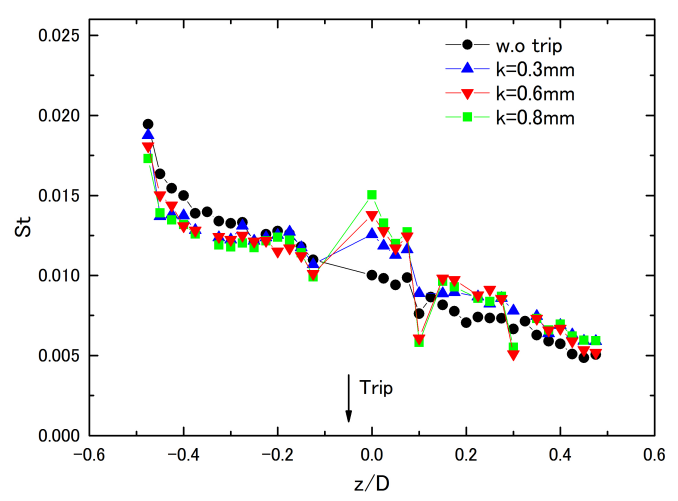

(e) Condition E: $H_{0}=13 \mathrm{MJ} / \mathrm{kg}, R e / l=1.3 \mathrm{E} 6 / \mathrm{m}$

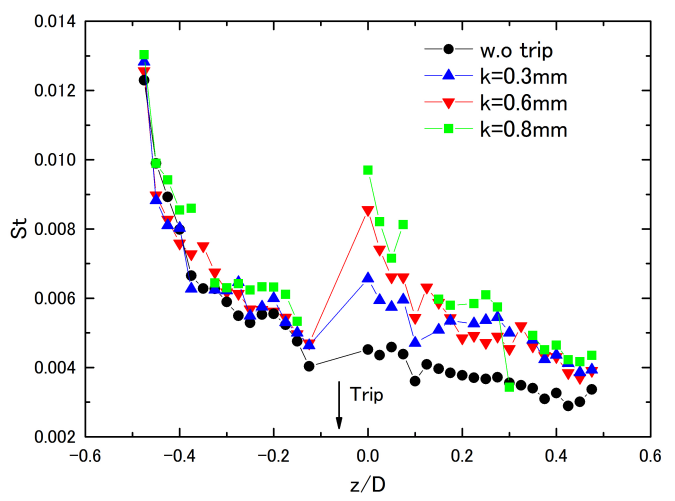

(b) Condition B: $H_{0}=5.1 \mathrm{MJ} / \mathrm{kg}, R e / l=2.6 \mathrm{E} 6 / \mathrm{m}$

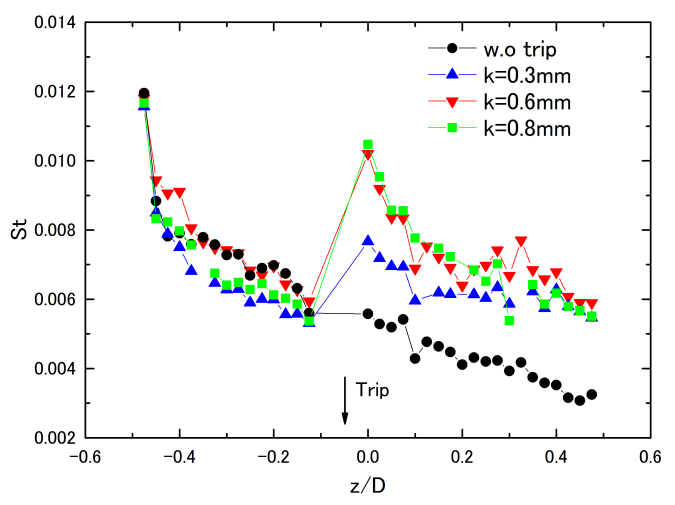

(d) Condition D: $H_{0}=9.0 \mathrm{MJ} / \mathrm{kg}, R e / l=2.4 \mathrm{E} 6 / \mathrm{m}$

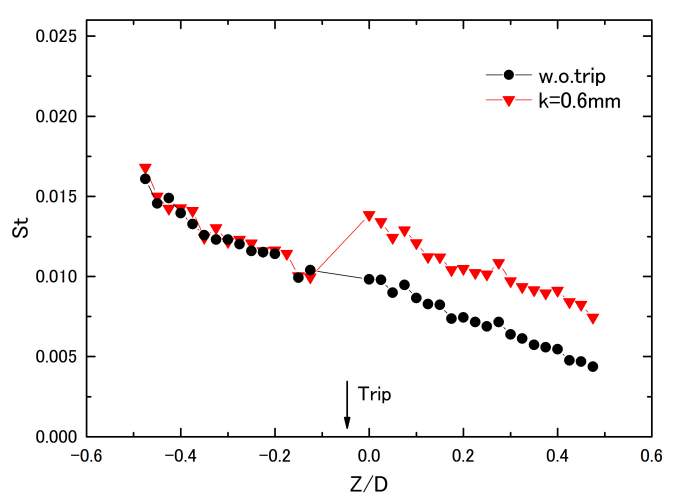

(f) Condition F: $H_{0}=12 \mathrm{MJ} / \mathrm{kg}, R e / l=2.4 \mathrm{E} 6 / \mathrm{m}$ 


\section{EXPERIMENTAL INVESTIGATION OF ROUGHNESS EFFECTS ON TRANSI- TION ON BLUNT SPHERICAL CAPSULE SHAPES}

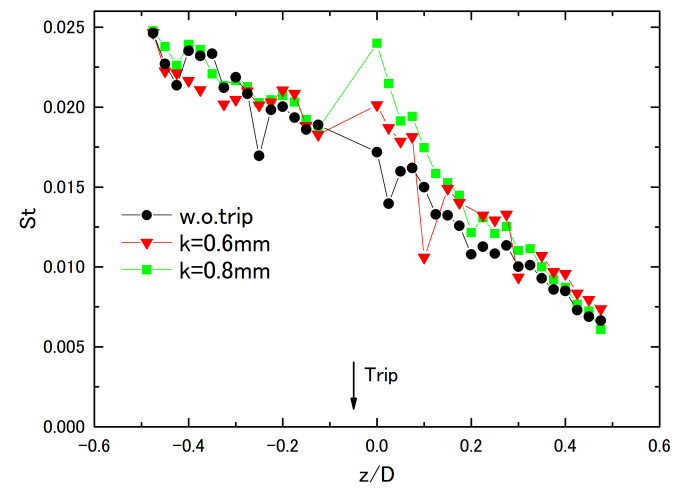

(g) Condition G: $H_{0}=21 \mathrm{MJ} / \mathrm{kg}, R e / l=8.4 \mathrm{E} 5 / \mathrm{m}$

Figure 9-23: Heat flux distribution on heat-shield surface with isolated roughness elements.

It is interesting that the location where the heat flux increased without roughness (i.e. the natural transition point) is found at $z / D=-0.16$, which is upstream from the roughness element $(z / D=-0.068)$. Yet in the heat flux distributions with roughness elements, a heat flux jump is observed at $z / D=0$, which is the closest thermocouple location downstream from the roughness. Since the location of the heat flux increase point on a smooth surface often shows dispersion, even under identical flow conditions, the difference in location with and without roughness appears reasonable. Since the region downstream from $z / D=0.25$ shows the same heat flux (not significantly different) both with and without roughness, it appears that the boundary layer changes to fully turbulent flow in both cases. It is therefore concluded that the roughness elements were effective under the present free-stream conditions and that a turbulent boundary layer was successfully established with $k=0.6 \mathrm{~mm}$ roughness elements.

The effect of roughness height for flow condition $\mathrm{B}$ to $\mathrm{F}$ is now discussed, by comparing the measured heat flux distribution profiles. Figure 9-23 (b), (c) and (d) display the profiles of heat flux distribution up to $H_{0}=9$ $\mathrm{MJ} / \mathrm{kg}$, which show onset of turbulence flow in the presence of the roughness elements. In these figures, all the roughness elements are effective because the there is no significant difference in the heat flux downstream of different roughness elements $(z / D=0.2$, or downstream). However, there is an undesirable heat flux overshoot in downstream regions near roughness elements. According to the comparison of heat flux distribution profiles, a roughness element with $\mathrm{k}=0.3 \mathrm{~mm}$ is the best choice for tripping because it showed minimum overshoot. At the much higher $H_{0}$ with lower Reynolds number (Condition E: $H_{0}=13 \mathrm{MJ} / \mathrm{kg}$ and Condition F: $H_{0}=20 \mathrm{MJ} / \mathrm{kg}$ ) shown in Figure 9-23 (e) and (g), a heat flux jump is found at the vicinity of roughness elements. However, the expected heat flux due to a turbulent boundary layer in the downstream region is not observed even with the highest roughness elements $\left(k=0.8 \mathrm{~mm}\right.$ ). At the maximum $P_{0}$ (Condition F) as shown in Figure 9-23 (f), the roughness elements are effective to induce the onset of transition, indicating that boundary layer tripping was achieved at $H_{0}=12 \mathrm{MJ} / \mathrm{kg}$.

\subsection{ANALYSIS}

The transient growth theory for stagnation point flow advanced by Reshotko and Tumin [9] has provided a successful correlation for the observed roughness-induced transition on spherical forebodies including the PANT experiments done in wind tunnels [10], [11] and the Reda experiment done in a ballistic range [35],[36] as Figure 


\section{EXPERIMENTAL INVESTIGATION OF ROUGHNESS EFFECTS ON TRANSITION ON BLUNT SPHERICAL CAPSULE SHAPES}

9-24 shows. The transition on blunt entry shapes such as the Apollo and CEV configurations is also dominated by stagnation point flow. It has been shown that for these configurations at angle-of-attack, the flow is T-S stable and the crossflow is insignificant. Hence, a plausible mechanism for transition is roughness induced transient growth. The Reshotko-Tumin theory shows that the maximum transient growth occurs in the near vicinity of the stagnation point, at Mach numbers up to about 0.3. This is confirmed in the recent PSE studies of Parades et al of NASA-Langley, and the even more recent studies of Theiss and Hein of DLR-Gottingen that are in agreement with the NASA-Langley studies [15].

All of the experiments done within the present work involve the Apollo/CEV windward geometry at angle-

Table 9-5: Flow parameters of transient-growth correlation in selected transition experiments

\begin{tabular}{ccccc}
\hline \hline Source & $\mathrm{T}_{w} / T_{e}$ & $\begin{array}{c}\text { assumed value } \\
180\left(T_{e} / 2 T_{w}\right)^{-1.27}\end{array}$ & $\begin{array}{c}\text { transition onset } \\
\operatorname{Re}_{\theta}\end{array}$ & $\begin{array}{c}\text { transition onset } \\
\mathrm{k} / \theta\end{array}$ \\
\hline PANT & $0.45-0.55$ & 180 & $20-100$ & $1.7-20$ \\
Reda & $\approx 0.3$ & 106 & $25-200$ & $0.5-3$ \\
$\begin{array}{c}\text { ACE, stochastic } \\
\text { roughness }\end{array}$ & $0.95-0.96$ & 405 & $23-45$ & $8-17$ \\
$\begin{array}{c}\text { HLB, deterministic } \\
\text { subcritical roughness } \\
\text { HLB, stochastic } \\
\text { roughness }\end{array}$ & $0.69-0.74$ & 280 & $220-240$ & $0.45-0.6$ \\
\hline
\end{tabular}

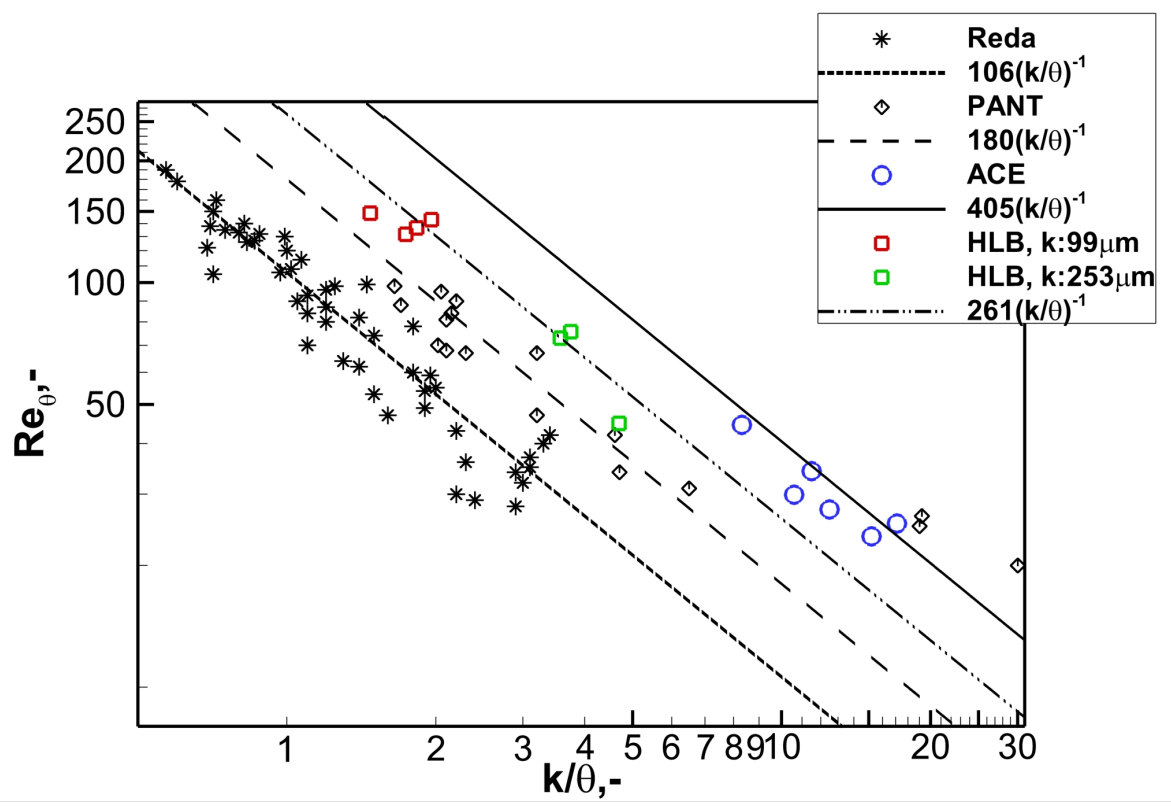

Figure 9-24: Transient growth based transition data comparison

of-attack. For the ACE Tunnel experiment (Chapter 9.2) and the HIEST experiment (Chapter 9.4) the angleof-attack was $28 \mathrm{deg}$. For the HLB experiment (Chapter 9.3), the angle-of-attack was $24 \mathrm{deg}$. All reported measurements are evaluated along the center plane-of-symmetry of the models. Typical flow parameter of the 


\section{EXPERIMENTAL INVESTIGATION OF ROUGHNESS EFFECTS ON TRANSI- TION ON BLUNT SPHERICAL CAPSULE SHAPES}

experiments with distributed roughness are given in Table 9-5.

For the ACE experiment, the roughness was applied quasi-uniformly over the whole front surface of the model, consistent with what was done in the PANT and Reda experiments. Their results are reasonably well correlated by the Reshotko-Tumin theory. Their observed transition locations are between $\mathrm{y} / \mathrm{R}$ of -0.45 and 0.30, upstream of the center point of the model. This was a somewhat difficult experiment because of the low Reynolds number range of the tunnel and also that the transient growth is weakest near adiabatic wall temperatures. Thus, the roughness heights needed to obtain the observed transitions on the model were of the order of 0.7 to 1.5 boundary-layer thicknesses.

In the HLB experiments, two different types of roughness were applied. One roughness patch, $20 \mathrm{~mm}$ x 20 $\mathrm{mm}$ was placed about the geometric center of the $170 \mathrm{~mm}$ diameter model. The stagnation point for this model at $24 \mathrm{deg}$ angle-of-attack is $59 \mathrm{~mm}$ upstream of the center of the model. At the beginning of the roughness patch, the local Mach number is 0.43 so that the roughness begins downstream of the region of maximum transient growth. The level of freestream disturbances could be varied during these experiments within a certain range by varying model position in the tunnel. Table 6 shows that relative roughness heights at transition and transition Reynolds numbers would cluster at the upper left corner of Figure 9-24, rather far away from the transient growth correlation. Based on the results, the authors assume that the observed transitions that occur about 20-25 $\mathrm{mm}$ downstream of the roughness patches are due to freestream disturbances in the tunnel, which interact with subcritical roughness. This set of experiments does not indicate roughness induced transient growth. The second set of roughness experiments in HLB was conducted with patches of larger roughness height. The roughness elements were stochastically distributed and covered a $30 \mathrm{~mm}$ wide band over the entire capsule front. Figure 9-24 confirms, that transition locations derived from these experiments, which employed two patches with different roughness height, correlate reasonably well with transient growth theory, while varying freestream disturbances by changing model position in the tunnel resulted in only a minor effect on transition.

The HIEST experiment had a different objective, namely to study the effectiveness of a trip located just upstream of the geometric center of the model. The trip is located at $z / R=-0.034$ where the local Mach number is about 0.53 . This is well downstream of the region of maximum transient growth. Thus transient growth is not a factor in this work. At the highest capsule Reynolds number of $1.2 \cdot 10^{6}$, transition is observed on the model even

without a trip. For all lower capsule Reynolds numbers, without a trip, the flow remains laminar. For capsule Reynolds numbers between $0.6 \cdot 10^{6}$ and $1 \cdot 10^{6}$, with trips of height $0.3 \mathrm{~mm}$ to $0.8 \mathrm{~mm}$, the boundary layer is tripped and turbulent heat transfer levels are sustained. So, in these cases, the trips can be considered as effective. For capsule Reynolds numbers of $0.4 \cdot 10^{6}$ and smaller, a heat flux jump was found just downstream of the trip but the heat fluxes returned to laminar levels. In these cases, the trip was not effective. As shown in Figure 9-25, for these cases where the trips were not effective, the $R e_{k k}$ was as high as 590 for the $0.8 \mathrm{~mm}$ trip height, but the capsule Reynolds numbers were at the low end of all the tests. From Figure 9-25 it is seen that trip effectiveness depends primarily on capsule Reynolds number. However to be noted is that the stagnation enthalpies, $H_{e}$, all exceed $2 \mathrm{MJ} / \mathrm{kg}$ so that the air is no longer a perfect gas. As $H_{e}$ increases, the surface temperature levels, $T_{w} / T_{e}$ decrease while the roughness Reynolds numbers $R e_{k k}$ increase slightly, these are effects of chemistry. So while trip effectiveness depends primarily on capsule Reynolds number, the effects of chemistry make tripping slightly more difficult. 


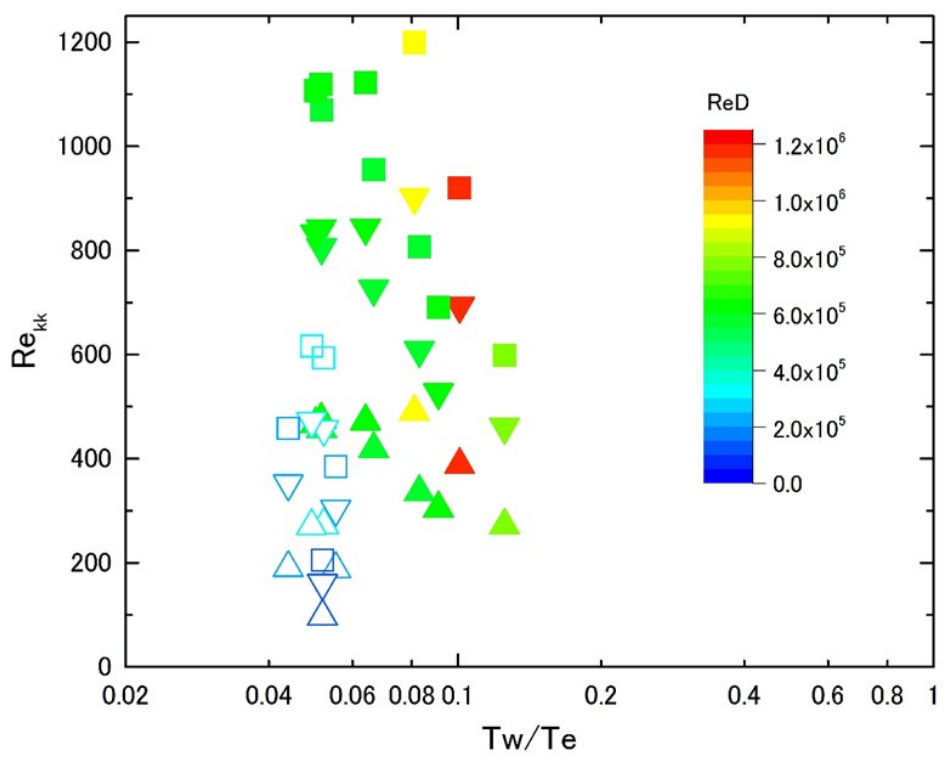

Figure 9-25: Trip effectiveness for various stagnation enthalpies and capsule Reynolds numbers. Filled symbols denote effective tripping.

\subsection{CONCLUSION}

The present contribution reviews recent experimental results of roughness effects on boundary layer transition on capsule geometries with spherical windward geometries. Experiments in three wind tunnel facilities are considered. The ACE Tunnel of Texas AM University, USA, provided Mach 6 experiments with distributed roughness at relatively low Reynolds numbers, $2.5 \cdot 10^{5}<R e_{d}<5 \cdot 10^{5}$, with d denoting the capsule diameter. The observed boundary layer transition compared well with correlations based on transient growth theory, even though the roughness heights were in the order of boundary layer thickness. Larger Reynolds numbers, $1 \cdot 10^{6}$ $<R e_{d}<3 \cdot 10^{6}$, could be assessed in the hypersonic Ludwieg tube, HLB, of TU Braunschweig, Germany. Transition is observed at rather low, subcritical roughness values in the order of $20 \mu \mathrm{m}$ for a roughness patch placed about the geometric center of the capsule model. These experiments varied fluctuation levels of the freestream. The authors assume that the observed transitions that occur downstream of the subcritical roughness patch are due to freestream disturbances in the tunnel, which interact with small roughness heights. Additional experiments in the HLB facility with patches of larger roughness height support the relevance of transient growth theory for low-to-medium roughness heights, relative to boundary layer thickness. The effects of Reynolds numbers and total flow enthalpy on transition with isolated roughness were investigated in the HIEST facility of JAXA, Japan. Here, a model insert with roughness elements of varying height for tripping transition to turbulence was employed. The results are compared to known trip effectiveness correlations for isolated roughness. Overall, the transient growth correlation seems to represent roughness-induced transition behavior on the ACE and HLB entry capsule shapes with roughness over the entire capsule surface. These experiment are however for perfect gases. Comparable experiments on roughness induced transition in a high-enthalpy facility are still 


\section{EXPERIMENTAL INVESTIGATION OF ROUGHNESS EFFECTS ON TRANSI- TION ON BLUNT SPHERICAL CAPSULE SHAPES}

needed to confirm the validity of transient-growth correlation for vehicle design.

\subsection{ACKNOWLEDGMENTS}

The authors of TU Braunschweig received funding by the German Research Association, DFG, within the HYPTRANS PAK742 project and by EOARD, Award No. FA9550-16-1-0285.

\subsection{REFERENCES}

[1] Hollis, B., Berger, K., Horvath, T., Lillard, R., Coblish, J., Norris, J., and Kirk, B., "Aeroheating Testing and Predictions for Project Orion Crew Exploration Vehicle," Spacecraft and Rockets, Vol. 46, No.4, 2009.

[2] Marineau, E., Lewis, D., Lafferty, J., White, M., and Amar, A., "Investigation of Hypersonic Laminar Heating Augmentation in the Stagnation Region," AIAA paper 2013-308, 2013.

[3] Ali, S., Radespiel, R., and Theiss, A., "Transition Experiment with a Blunt Apollo Shape like Capsule in Hypersonic Ludwieg Tube,” DLRK paper 2014-340270, 2014.

[4] Amar, A., Horvath, T., Hollis, B., Berger, K., Berry, S., and Calvert, N., "Protuberance Boundary Layer Transition for Project Orion Crew Entry Vehicle," AIAA paper 2008-1227, 2008.

[5] Theiss, A., Hein, S., Ali, S.R.C., and Radespiel, R., "Wake flow instability studies behind discrete roughness elements on a generic re-entry capsule," AIAA paper 2016-4382, 2016.

[6] Tanno, H., Komuro, T., Sato, K., Itoh, K., Lillard, R., and Olejniczak, J., "Aeroheating measurements of Apollo-shaped capsule with boundary layer trip in the free-piston shock tunnel HIEST," AIAA paper 2014-0434, 2014.

[7] Kirk, L., Lillard, R., Olejniczak, J., and Tanno, H., "Boundary Layer Transition and Trip Effectiveness on an Apollo Capsule in the JAXA High Enthalpy Shock Tunnel (HIEST) Facility," AIAA paper 2015-0209, 2015.

[8] Reshotko, E. and Tumin, A., "The Blunt Body Paradox - A Case for Transient Growth," Laminar-Turbulent Transition, edited by H. Fasel and W. Saric, Springer, 2000, pp. 403-408.

[9] Reshotko, E. and Tumin, A., "Role of Transient Growth in Roughness-Induced Transition," AIAA Journal, Vol. 42, No.4, 2004.

[10] Batt, R.G. and Legner, H.L., "A Review and Evaluation of Ground Test Data on Roughness Induced Nosetip Transition," Ballistic Missile Office/SYDT, Rept. BMD-TR-81-58, Norton AFB, CA, 1980.

[11] Batt, R.G. and Legner, H.L., “A Review of Roughness-Induced Nosetip Transition,” AIAA Journal, Vol. 21, No.1, 1983.

[12] Hollis, B., "Distributed Roughness Effects on Blunt-Body Transition and Turbulent Heating Speeds," AIAA paper 2014-0238, 2014.

[13] Hollis, B., "Correlation of Recent and Historical Rough-Wall Transition Data on Hemispherical Nosetips," AIAA paper 2017-3986, 2017. 


\section{EXPERIMENTAL INVESTIGATION OF ROUGHNESS EFFECTS ON TRANSITION ON BLUNT SPHERICAL CAPSULE SHAPES}

[14] Leidy, A.N., Reshotko, E., Siddiqui, F., and Bowersox, R.D.W., "Transition Due to Roughness on Blunt Capsule: Comparison with Transient Growth Correlation,” Journal of Spacecraft and Rockets, 2017.

[15] Hein, S., Theiss, A., Di Giovanni, A., Stemmer, C., Schilden, T., Schröder, W., Paredes, P., Choudari, M.M., Li, F., and Reshotko, E., "Numerical Investigation of Roughness Effects on Transition on Spherical Capsules," AIAA paper 2018-0058, 2018.

[16] Duan, L., Choudari, M., Chou, A., Munoz, F., Ali, S., Radespiel, R., Schilden, T., Schröder, W., Marineau, E., Casper, K., Chaudhry, R., Candler, G., Gray, K., Sweeney, C., and Schneider, S., "Characterization of Wind Tunnel Freestream Disturbances in Conventional Hypersonic Wind Tunnels," AIAA SciTech-paper $2018,2018$.

[17] Estorf, M., Wolf, T., and Radespiel, R., "Experimental and numerical investigations on the operation of the hypersonic Ludwieg Tube Braunschweig," Proceedings 5th European Symposium on Aerothermodynamics for Space Vehicles, Vol. ESA SP-563, 2005, 2004, pp. 579-586.

[18] Heitmann, D., Kähler, C., Radespiel, R., Rödiger, T., Knauss, H., and Krämer., E., "Disturbance-level and transition measurements in a conical boundary layer at Mach 6," AIAA paper 2008-3951, 2018.

[19] Ali, S., R., R., Schilden, T., and Schröder., "High-Frequency Measurements of Acoustic and Entropy Disturbances," AIAA paper 2014-2644, 2014.

[20] Theiss, A., Hein, S., Heitmann, D., Ali, S., and Radespiel, R., "Numerical and experimental investigation of laminar-turbulent boundary layer transition on a blunt generic re-entry capsule," AIAA paper 2014-2353, 2014.

[21] Bernardini, M., Pirozzoli, S., Orlandi, P., and Lele, S.K., "Compressible boundary layer transition induced by isolated roughness elements," Proceedings of CTR Summer Program 2012, pages 15-24, 2012.

[22] Schultz, D.L. and Jones, T.V., "Heat Transfer Measurements in Short Duration Facilities," AGARD Rept. 165, 1973.

[23] Laufer, J. and Mcclellan, R., "Measurements of heat transfer from fine wires in supersonic flows," Journal of Fluid Mechanics, Vol. 1, No.3, 1956, pp. 276-289.

[24] Itoh, K., Ueda, S., Tanno, H., Komuro, T., and Sato, K., "Hypersonic Aerothermodynamic and Scramjet Research Using High Enthalpy Shock Tunnel,” Shock Waves, Vol. 12, 2002, pp. 93-98.

[25] Hornung, H. and Belanger, J., "Role and techniques of ground testing for simulation of flows up to orbital speed," AIAA paper 1990-1377, 1990.

[26] Tanno, H., Komuro, T., Sato, K., Itoh, K., Yamada, T., Sato, N., and Nakano, H., "Heat flux measurement of Apollo capsule model in the free-piston shock tunnel HIEST," AIAA paper 2009-7304, 2009.

[27] Sanderson, S. and Sturtevant, B., "Transient heat flux measurement using a surface junction thermocouple," Rev. Sci. Inst., Vol. 73, No.7, 2002.

[28] Marineau, E. and Hornung, H., "Modeling and Calibration of Fast-Response Coaxial Heat Flux Gages," AIAA paper 2009-737, 2009.

[29] Berger, K., "Aerothermodynamic Testing of the Crew Exploration Vehicle in the LaRC 20-Inch Mach 6 and 31-Inch Mach 10 Tunnels," AIAA paper 2008-1225, 2008. 


\section{EXPERIMENTAL INVESTIGATION OF ROUGHNESS EFFECTS ON TRANSI- TION ON BLUNT SPHERICAL CAPSULE SHAPES}

[30] Marineau, E., Laurence, S., and Hornung, H., "Apollo-shaped capsule boundary layer transition at highenthalpy in T5," AIAA paper 2010-446, 2010.

[31] Kirk, L., Lillard, R., Olejniczak, J., and Tanno, H., "Boundary Layer Transition and Trip Effectiveness on an Apollo Capsule in the JAXA High Enthalpy Shock Tunnel (HIEST) Facility," AIAA paper 2015-0209, 2015.

[32] Prabhu, R. and Erickson, W., "A Rapid Method for the Computation of Equilibrium Chemical Composition of Air to $15000 \mathrm{~K}, " N A S A$ TP-2792, 1988.

[33] Takahashi, M., Kodera, M., Itoh, K., Komuro, T., Sato, K., and Tanno, H., "Influence of Thermal NonEquilibrium on Nozzle Flow Condition of High Enthalpy Shock Tunnel HIEST," AIAA paper 2009-7267, 2009.

[34] Tanno, H., Komuro, T., Lillard, R., and Olejniczak, J., "Experimental Study of High-Enthalpy Heat Flux Augmentation in Shock Tunnels," Journal of Thermophysics and Heat Transfer, Vol. 29, No. 4, 2015.

[35] Reda, D.C., "Correlation of Nosetip Boundary-Layer Transition Data Measured in Ballistic Range Experiments," AIAA Journal, Vol. 19, No. 3, 1981, pp. 329-339.

[36] Reda, D.C., "Review and Synthesis of Roughness-Dominated Transition Correlations for Reentry Applications," Journal of Spacecraft and Rockets, Vol. 39, No. 2, 2002, pp. 161-167. 